\title{
الإطار القانوني للاقتصاد التعاوني عبر المنصات الإليكترونية
}

\author{
بجاث مفره الى مؤهر \\ الجوانب القانونيتّوالاقتصاديتّللذهاء الاصطناعي \\ وتكنولوجيا المعلومات

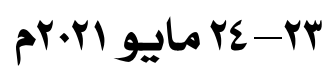 \\ كليتًا الحقوق- جامعت المنصورة \\ shel \\ أ.د / محمد محمد عبد اللطيف \\ أستاذ القانون العام \\ كليتالحقوق_جامعت المنصورة
}


عدد خاص بالمؤتمر الدولى السنوى العشرون أ.د / محمد محمد عبد اللطيف

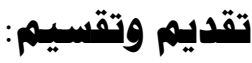

أصبح الاقتـصاد التعـاوني عبر المنـصات الإليكترونيـة، أو الاقتصاد الرقــي

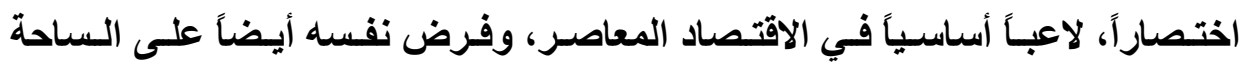

القانونية.

وبطبيعـة الحسال يعـد تعريـف الاقتصاد التعـاوني أو الاقتـــاد الرقــي أولـى

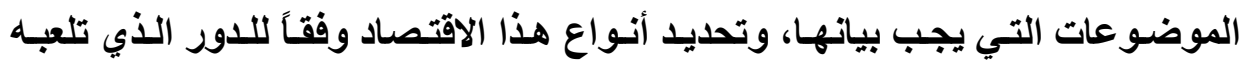
المنصات الإليكترونية، وهو دور متابين إلى حد كبير.

وتأتي بعد ذلك المشكلة الكبرى التي تتمثل في تنظيم الاقتصاد التعاوني عبر

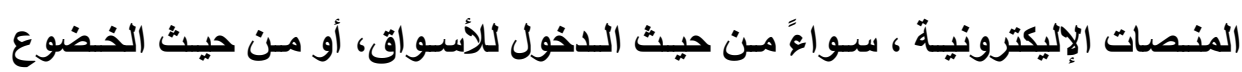
للمنافسة، واخيراً الخضوع للقانون الضريبي.

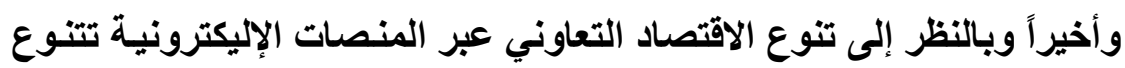
أيضاً بل وتتداخل العلاقات التعاقدية بثكل كبير، وهو أمر يجب التعرض له قبل التبل الوصول إلى نهاية هذا البحث. وبناءً على ذلك نبحث موضوع الاقتصاد الرقمي من خلال الخطة الآتية: المبحث الأول: مقومات الاقتصاد الرقمي المبحث الثاني: تنظيم الاقتصاد الرقمي المبحث الثالث: العلاقات التعاقدية للاقتصاد الرقمي 
عدد خاص بالمؤتمر الدولى السنوى العشرون أ.د / محمد محمد عبد اللطيف

\section{المبحث الأول}

هقومات الاقتصاد الرقمي

حتــى يمكـن عـرض مقومسـات الاقتهـصاد الرقـــي علينــا أولا تعريفـهـ وبيــان

أنواعه(المطلب الأول) ،ثم بيان مفهوم المنصات الرقمية وأنواعها(المطلب الثاني).

المطاب الأول

\section{تعريف الاقتصاد الرقمي وأنواعه}

تعريف الاقتصاد التعاوني: L'économie collaborative

الاقتصاد التعاوني نموذج اجتماعي واقتصادي جديد، ويعتمد على المشاركة أو

تبادل السلع أوالخدمات أو المعرفة بين الأفراد، ويترجم بتبادل نقدي أو غير نقدي. ومع ذلك يمكن تعريفه على أنه نموذج اقتصادي يعتمد جوهرياً على استهلاك تعاوني للسلع والخـدمات التـي تستخدم بشكل غيـر كـاف ويقدمها أفراد غيـر محترفين مسن خـلال المنصات الرقمية(')،لأفراد آخرين غير محترفين أيضاً(؟).

ويعرف الاقتصاد الرقمي أيضاً على أنه نشاط إنساني يهـف إلى إنتاج قيمة

مشتركة، ويستند إلى أشكال جديدة في تنظيم العمل، ويعتمد على تنظيم أفقي أكثر من التنظيم الرأسسي، وتجميع السلع والخدمات والمساحاتو الأدوات، انطلاقًاً مـن منطلق

(1) «Plateforme numérique »

(2) P.Van Cleynenbreugel, Le droit de l'Union européen face à l'économie collaborative, RTD Eur.,, 2017 , p.697.

مجلتة البحوث القانونيت والإقتصاديتة 
عدد خاص بالمؤتمر الدولى السنوى العشرون أ.د/ محمد محمد عبد اللطيف

الاستعمال وليس الحيـازة، ووتنظيم المواطنين في شبكة أو في جماعات، والوسـاطة عموماً من خلال منصات إنترنت (1).

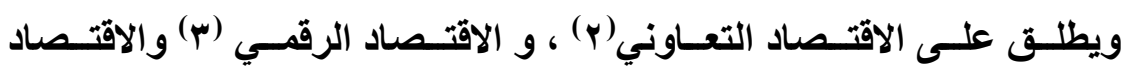

التشاركي(ع)، أو الاقتصاد بين النظراء، أو من نظير إلى نظير(ه) ، أو حتى اقتصاد

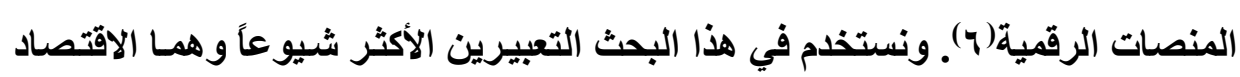
الرقمي، والاقتصاد التعاوني، والتعبير الثاني هو الأكثر استعمالاً في الفقه الفرنسي.

التمييز بـين الاقتصاد التعـاوني والاقتصاد الرقمسي واقتصاد المنـصات

تميز بعض الكتابات بين تعبيرات ثُلاث: الاقتصتد التعاوني، واقتصاد المنصات

$$
\text { الإليكترونية، والاقتصاد الرقمي (v). }
$$

فالاقتصاد التعاوني économie collaborative/ cooperative يقوم على فكرة العطاء المجـانيdon ، وإنتـاج السلع المشتركة، ويجمع متعـاونين متطوعين في إنتاج الأموال والمعرفة والأفكار واقتسامها بحرية.وتحتل فكرة المجانية مكانة مركزية.

(1) X.Delpech, L'assurance dans les transports de personnes de l'economie collaborative :le cas de covoiturage, Juris Tourisme, 2020,n.235,28p.

(2) « Economie collaborative»

(3) « Economie numérique »

(4) « Economie du partage»

(5) « Economie entre paires, paire to paire »

(6) « Economie de plateforme »

(7) A.Magha et M.Vitello, Réguler l'économie numérique, 2017,p.2 
عدد خاص بالمؤتمر الدولى السنوى العشرون أ.د / محمد محمد عبد اللطيف

واقتصاد المنصـات الرقميـة économie de plateforme هـو الذي تـم

تشييده اعتمـاداً على منصـات إليكترونيـة تقوم بـدور الوسـيط بـين العمـلاء ومقدمي

الخدمات المادية. وفي هذا النوع من الاقتصاد ليس الأمر المركزي هو الإنتاج المشترك لوك

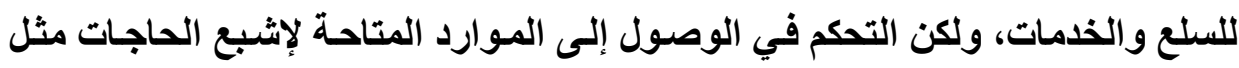

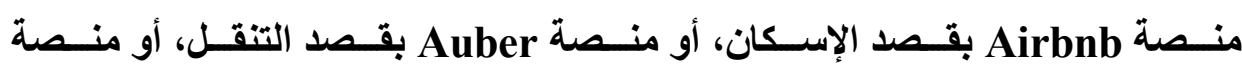

Deliveroo

وتستخدم هذه المنصات نظم البيانـات الضخمة Big Data و الخوارزميـات

؛للوصـول إلـى الوضــع المثـل optimisation للعـرض والطلـب ؛ خـصوصاً لأنهـا مملوكمة من مجموعات مالية رأسمالية تقوم بتجريب أشكال اقتصادية جديدة ، تحل بمقتضاها أشكال جديدة من المشاركة غير المستقرة محل العمل المأجور المنظم قانوناً. وأما الاقتصاد الرقمي économie numérique/digitale فهو يعتمد أيضاً على منصات إليكترونية تربط الموردين بطالبي الخدمات التي يمكن تبادلها في شكل

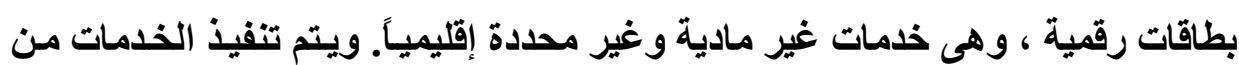
شخص متجول نظير أجر.

وهذا التمييز بين هذه الأنواع الثلاثة للاقصاد هو تمييز نسبي أو تحكمي ، وسوف نرى مدى التعقيد في ظاهرة الاقتصاد التعوني أو الرقـي إلى درجة أن الفقهـ الغالب لايميز بين الاصطلاحات الثلاثة ، لكنه يكتفي بمحاولة إبراز مختلف الأدوار التي تؤديها على النحو الأي سنبينه بعد قليل.. أهمية الاقتصاد الرقمي:

وتطلق منظمة التعاون والتنمية الاقتصادية تعبير الاقتصاد الرقمي، وتقصد بـه

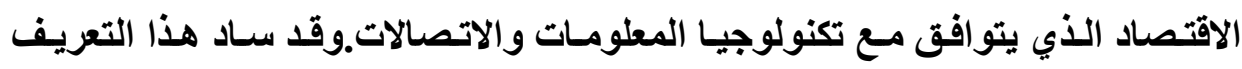


عدد خاص بالمؤتمر الدولى السنوى العشرون أ.د / محمد محمد عبد اللطيف

الضيق فـي مجـال الاقتصاد السياسي، لكنـه لا يسمع لنـا بفهم التحولات الاجتمـاعيـة والاقتصادية الناتجـة عن الانتشار السريع لهذه التقنيـات. وعلى العكس يرى بعض الكتاب أن الرأسمالية دخلت مرحلة جديدة تتمحور حول رؤوس أموال غير ماديـة أو معنوية،والمعرفة، ومن ثم التشكيك في آليـات التنظيم القائمـة على مبـادئ رأسـمالية

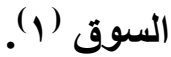

ومن الكتـاب من يركز على فكرة أن الاقتصاد التعاوني هو طريقة جديدة في الاستهلاك تعتمد على الاستعمال أكثر من الملكية، فالأفضل هو استعمال الأصول المادية وغير المادية التي يملكها الأفراد لتي غالباً ما يتم التهوين من قيمتها، وتفضيل استعمال الأموال عن تملكها، وتخفيض تكاليف الصفقات بين العرض والطلب. ونطـاق الاقتصاد التعـاوني واسـع جداً، ويصعب تعريفـه بدقة. ومـع ذلكـ فهو يتجسد في تمكين أى شخص في عرض سلع أو خدمات عبر الإنترنت وتحديداً من خلال

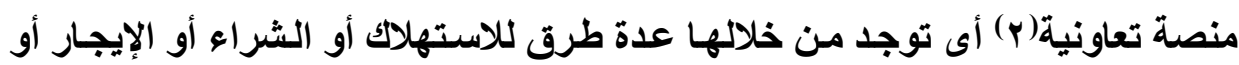
عرض خدمات، أو تقديم اموال. ومن هنا فقد تعددت المنصات تعدداً كبيراً في مجالات كثيرة ومتنوعة(ب) ، ومنـه على سبيل المثال: نقل الأثـخاص والبضائع، والتمويل، والضيافة العارضة، وتبادل الخدمات.

ويعيش الاقتصاد التعاوني الآن مرحلة احتراف عالية؛ بفضل المنصات الرقمية المتخصصة في التوسط بين مقدمي الخدمات ومتلقي الاقتصاد التعاوني. ويشار بشكل

(1) A.Courmont, Economie numérique, Dictionnaire d'economie politique, 2018,p.187

(2) « Plateforme collaborative»

(3)A. Fortunato, La relation contractuelle collaborative, RTD com.2019, p.19 
عدد خاص بالمؤتمر الدولى السنوى العشرون أ.د / محمد محمد عبد اللطيف

خاص إلى بعض المنصات في لعب دور أكثر نشاطاً، بحيث أصبحت أكثر مشاركة في

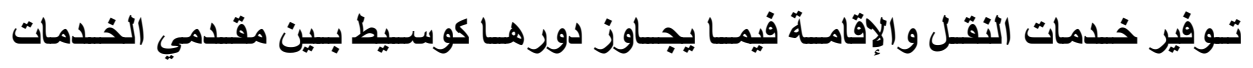
والمستفيدين منها. ويقار أن الاقتصاد التعـاوني عبر المنصات الرقمية يمثل في العـام

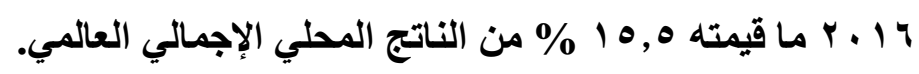

باختصـار يمكن تعريف الاقتصاد التعـاوني بأنـه إدخـال الأطراف المعنيـة مـن مقدمي الأموال والخدمات ومستخدميها في علاقة من خلال منصة رقمية (1) . أنواع الاقتصاد التعاوني:

والاقتصاد التعاوني وإن كانت له مجالات كثيرة إلا أنه ليس نمطاً واحداً، و إنمـا يمكن أن نميز في داخله بين نوعين:

النوع الأول هوما يمكن أن نطلق عليه الاقتصاد التعاوني الجماعي() الأي يعتمد على تجميع الأمسوال والخدمات بين الأفراد دون البحث عن ربـح ، انطلاقًاً من فكرة

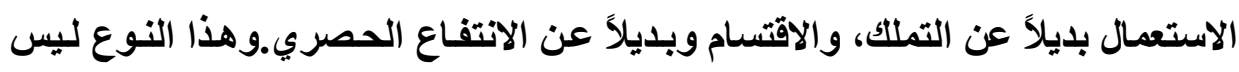
تجارياً ، وإنما هو أقرب إلى الاقتصاد التعاوني التقليدي économie mutualiste . والنوع الثاني هو الاقتصاد التعاوني المهني(") الذي وهو نمـذج جديد ينافس النماذج الاقتصادية التقليدية بفضل الجمع بين أدوات تكنولوجية، وتنظيم العمل. وهذا النموذج إذن يتميز بكونه مهني ويستهدف الربح، لكنه غير منظم ، أو يخضع لحد أدنى

(1) C.Minet-Letaile, A la une-Plateforme numérique-Qualification du contrat liant un livreur à une plateforme numérique :la Cour de cassation donne le ton, Juris tourisme, 2019, n.215, p.12

(2) « Economie collaborative communautaire»

(3) « Economie collaborative professionnelle » 
عدد خاص بالمؤتمر الدولى السنوى العشرون أ.د / محمد محمد عبد اللطيف

من التظظيم.ويوصف هذا النوع في فرنسا بأنه أوبري uberisée نسبة إلى الشركة الأمريكيـة أوبر Uber التي أحدثت أسـاليبها التقنيـة تغييراً كبيراً جعلها رمزاً لثورة اقتصادية مبدعة في المجال الرقمي.

وعلى الرغم من الفلسفة الاجتماعية التي قام من أجلها الاقتصاد التعاوني إلا أنها فيما يبدو بدأت في الاختفاء؛ بسبب تنامي الجهات العاملة ، والنمو المتسارع لكل قطاع.

\section{الإطلب الثاني}

هفهوم المنصات الرقمية ودورها في الاقتصاد الرقتمي

التعريف بالمنصات الرقمية:

أصبحت المنـصات الرقميـة(') تلعب دوراً كبيـراً في الحيـاة اليوميـة بـل وفـي

العلاقـات التجاريـة، وأصبحت العامـل المشترك في صسور الاقتصاد الرقمي. وأصبحت تسمح بإقامـة علاقات مباشرة بين مستخدمي الإنترنت.وأصبحت أيضاً بمثابـة العامل المشترك بين صور الاقتصاد التعاوني الذي يسمح بإقامة علاقة مباشرة بين مستخدي

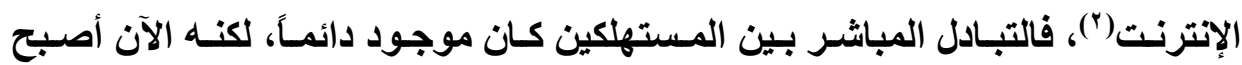

$$
\text { واسعاً إلى حد كبير بفضل المنصات الرقمية. }
$$

ولم يكن للاقتصاد التعاوني أن يحظى بالنجاح الأي وصل إليه دون ظهور عامل

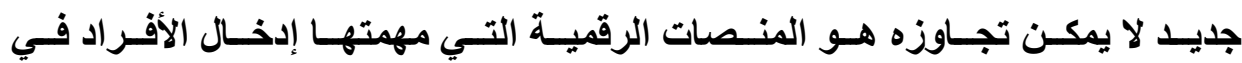

(1) «Plateformes numériques»

(2) Ph. Portier, Economie collaborative : faut-il vraiment règlementer ? Economie et management, n.159, 2016, p.6.

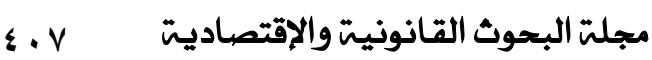


عدد خاص بالمؤتمر الدولى السنوى العشرون أ.د / محمد محمد عبد اللطيف

علاقة.وأصبحت المنصات قـادرة وحدها على تحقيق الالتقـاء بسهولة بين العرض

والطلب. وهذه الاعتبارات نجدها مطبقة تماماً في مجال نقل الأشخاص (').

وتأخذ المنصات الرقمية أشكالاً متتوعة، إنها تضم عدداً كبيراً من الخدمات،

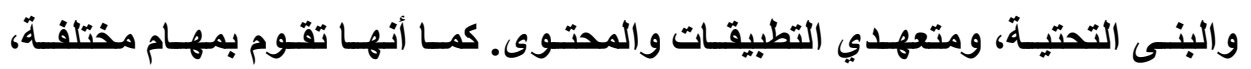

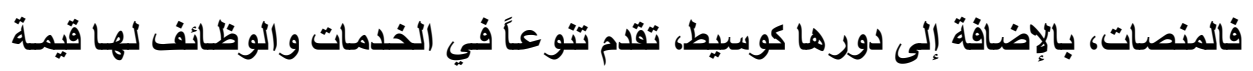

كبيرة :أنشطة تخزين تمر عبر خوادمها،أو تصنيف المحتوى، أو الدفع الآمن، ومزايـا

متعلقة بالأسعار.

وبالإضـافة إلى ذلك تضطلع المنصات بمسئولية وضع عدد من الأطراف في

علاقات معاً. وهذه العلاقات يمكن أن تتكون بين المنصة والمهنيين والمستهلكين، أو

بين المنصة والمستهلكين، أو بينها بطبيعة الحال والمهنيين. وإلى جانب هذا التعدد من

الأطراف يوجد أيضاً تنوع بين المستفيدين.

ويمكن القول: إن اقتصاديات المنصات الرقمية تعتمد على وجود هذا التعدد بين

الأطراف والأفراد، وهذا ما يجعل وضع تعريف لها أمراً بالغ الصعوبة؛؛ لأن هذا التعريف من شـأنه أن يعيد النظر في التمييز التقليدي بين الأطراف الثلاثة وهم مقدم الخدمـة فئة والمهنـي والمستهلك بإضـافة طرف آخر إلى هذه القائمسة. وعلى ذلك فالالتزامـات، والضمانات، والحماية الممنوحة لكل واحد منهم أصبحت محلاً لإعـادة النظر، ولـم تعد الحدود بينها كما كاتت من قبل فاصلة (ب).

(1) X.Delpech, précité .

(2) F.Sabrinni ,La notion de plateforme au cour des nouvelles relations entre professionnels ,RTD com. , 2020, p.2015

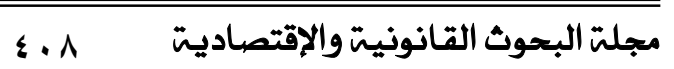


عدد خاص بالمؤتمر الدولى السنوى العشرون أ.د / محمد محمد عبد اللطيف

وقد تضمن تقتين الاستهلاك في فرنسا تعريفاً واسـعاً لمشغل المنصة الرقمية،

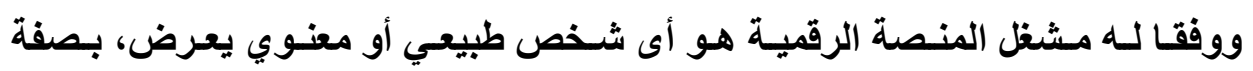

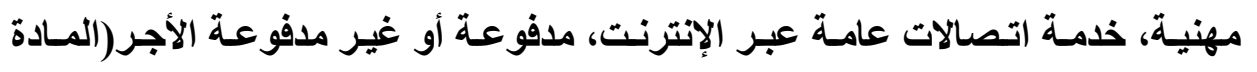

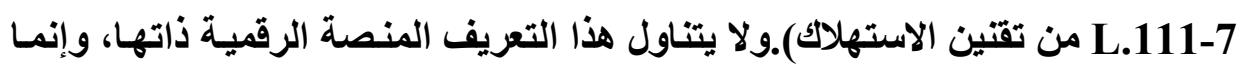
مشغل المنصة. وحتى الآن لا يوجد تنظيم قانوني خاص للمنصات الرقمية، وتزداد من وقت لآخر النداءات الخاصة بوضع هذا التنظيم، ووجود سلطة تتولى الرقابة والإثراف على على

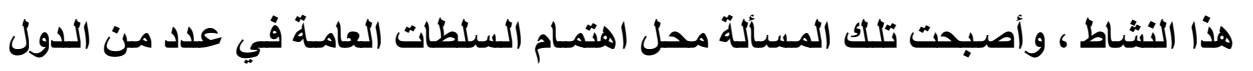
بالإضافة إلى الاتحاد الأوروبي (1). التقديم العام لأنواع المنصات الإليكترونية:

تدعم المنصات الرقمية علاقات ثلاثية جديدة تلتقي بفضل وساطتها، وتضع هذه المنصات علاقات بين المهنيين والمستهلكين، أو علاقات بين المستهرئين أو النظراء فقط. وأحياناً تضطلع المنصات الرقمية بجزء من النشاط الأي يقع على مقدم الخدمة

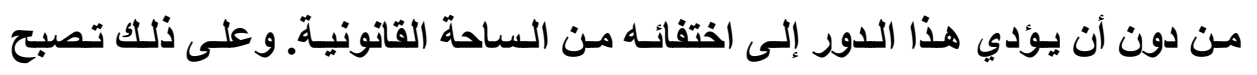

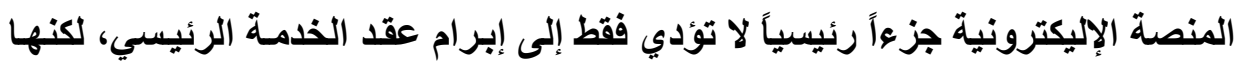

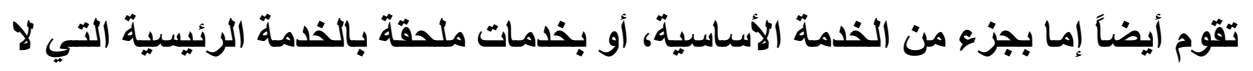

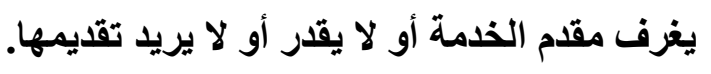

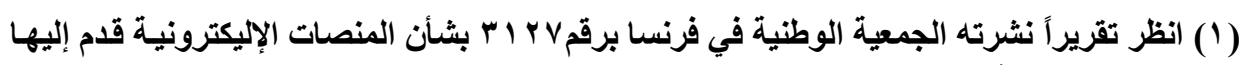

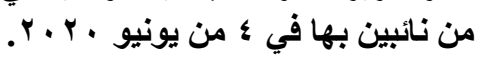

J.-M.Pastor, Pour une meilleure régulation des plateformes numériques structurantes , AJDA ,2020 ,p.1266

مجلتة البحوث القانونيت والإقتصاديت 
عدد خاص بالمؤتمر الدولى السنوى العشرون أ.د / محمد محمد عبد اللطيف

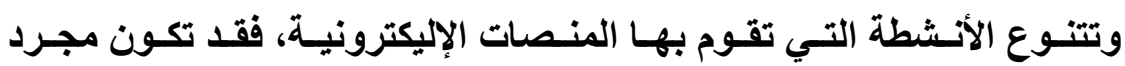

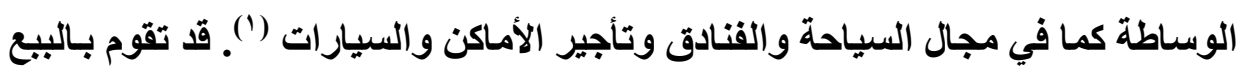

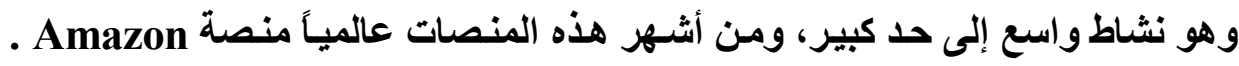
وقد تكون المنصات الإليكترونيـة منصات تمويل (r) أى تسهيل الحصول على على تمويل

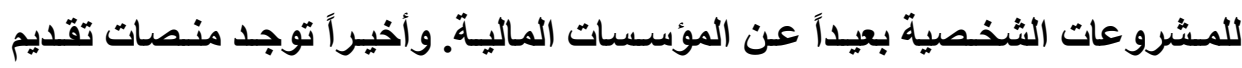

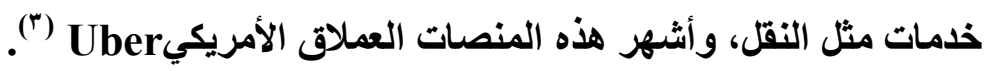
وهذا التقديم العـام لأنـواع المنـصات الإليكترونيـة لايمنـع مسن إجـراء عـرض

تفصيلي لهها.

التقديم التفصيلي لأنواع المنصات الإليكتونية: تتنوع المنصات الإليكترونية بحسب الدور الذي تؤديه(؛).

فقد تقوم المنصة أولا بتقديم منتج أو خدمـة، وتصبح هـ وليس غيرهـا مقدم

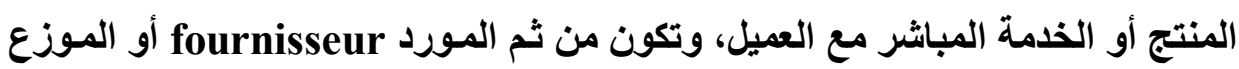

distributeur

(1) M.Blanchard ,Aspects de droit de la concurrence , Juris tourisme , 2016, p.32;A.Rière, La location entre particuliers à l'ère des plateformes numériques, AJ Contrat, 2018,p.206.

(2) « Crowdfunding »

(3)P.Van Cleynenbreugel, Le droit de l'Union européenne face à l'économie collaborative, RTD eur.,2017, p.697.

(4) J.Senechal, La diversité des services fournis par les plateformes en ligne et la spécifié de leur rémunération, un double défi pour le droit des contrat, AJ Contrat d'affaires, 2016,p.79. 
عدد خاص بالمؤتمر الدولى السنوى العشرون أ.د / محمد محمد عبد اللطيف

ومن أهم تطبيقات هذا النوع المنصات المسموعة والمرئية والموسيقية التي

تعتمد على دفع اشتراكات دوريـة تعطي الحق في اللدخول إليها سواءً كـان محدوداً أم

لا.ويبرم العقد بين مشغل المنصة والعميل. ويحصل الأخير على الخدمـة مـن خـلال

التحميل streaminig téléchargement، أو المشاهدة للميقي أو الفيديو.

وقد تقوم المنصة الإليكترونيـة ثانياً بـدو ر ممثل المسورد أو الوسبط ، ومقدم

الخدمة الملحقة والتابعة، لمصلحة العميل.

وفـي هــا الفرض الثـاني تكـون المنـصة الإليكترونيـة ممـثلاً لأحـــ الأطراف

المتعاقدة ، أو وسيطاً ، ومن ثم يبرم العقد بين المورد والعميل.وتقدم المنصة غالبـاً خدمة إبرام العقد عبر الإنترنت. وبعبارة أخرى لا تقدم المنصة بنفسها المنتج أو الخدمة ومدئ

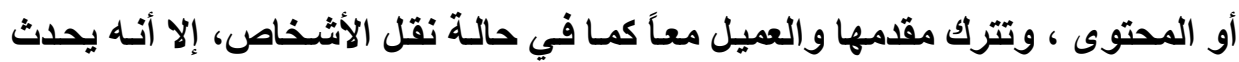
غالبًا أن تقترح هذه المنصات خدمات تكميلية تقع على المورد الذين يتفـاعلون من خلالها.وهذه الخدمات تتعلق بمرحلة التعاقد ومرحلة تنفيذ العقد مثل تقديم المعلومـات والعلانيـة السـابقة على التعاقد، وخدمـة الـدفع عبـر الإنترنـت، وإبـرام وثيقـة تـأمين الأضرار أو المسئولية لمصلحة المتعقدين المعنين، وخدمة الحراسة في مجال التأجير العقاري، وتحصيل الفواتير، وخدمة ما بعد البيع، والتسوية الودية للمناز عات.

وقد تقوم المنصة الإليكترونية، ثالثاً، بدور ممثل المورد أو الوسبط، مـع القيام

بوصفها متعاقداً مشاركاً cotraitant أو متعاقداً مـن البـاطن sous-traitant بتنفيذ الالتزام الرئيسي للمورد وهو التقديم الفعال للمنتج أو المحتوى الرقمي للعميل. وفي هذا الفـرض الثالث تسمح المنصة الرقميـة مسورد المنتج أو المحتوى الرقمي بأن يكون متعاقداً مباشراً مع العميل، لكنها تقصره على تنفيذ جوهر نشاطه مثل تصنيع المنتج، ونقل هذه البضاعة غلى مركز لوجستي، أو حتى تصميم محتوى رقمي 
عدد خاص بالمؤتمر الدولى السنوى العشرون أ.د / محمد محمد عبد اللطيف

في شكل تطبيق إليكتروني. وفيمـا يتعلق بهذا الجزء من الالتزامـات المفروضـة على المورد ، يقتصر دور المنصة على كونها ممثلاً له.

وإلى جاتب دورها ممثلاً للمورد يمكن ان تكون المنصة الإليكترونية إما متعاقداً مباشراً مع العميل، ومدينا بالالتزام الأساسي بالتوريد، وإما متعاقداً من البـاطن للمورد المكلف بالتنفيذ الفعال للالتزام بالتسليم أو بالتوريد.وتقوم المنصة الإليكترونية بصفتها

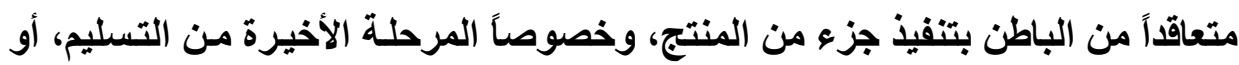
القيام بالتشغيل الفعال للمحتوى الرقمي، والتحكيم من ثم بالتنزيل أو الاطلاع الفعـال على المحتوى الرقمي.

وقد تقوم المنصات الإليكترونيـة، رابعـاً، إلى جانب كونهـا ممـثلاً للمـورد، أو وسيطاً، أن تكون أيضاً متعاقداً مشاركاً أو متعاقداً من الباطن بـالالتزام الرئيسي بتقديم المنتج أو المحتوى الرقمي، ولكن ايضاً بتقديم خدمات ملحقة ومكملة للالتزام الرئيس، وذلك لمصلحة العميل. وهـا الفـرض الذي يجمـع بـين الفرضسين السـابقين أى الثـاني والثالـث يمكن مشاهدته بسهولة في الواقع العملي في الأسواق عبر الإنترنت ومتجر التطبيقات. طبيعة منصة شركة أوبر: أثير التسـاؤل أمسام محكمة العدل للاتحساد الأوروبـي عمـا إذا كانت شـركة أوبر هber على العكس تعتبر نفسها شركة نقل. انتهت المحكمة، مسايرة المحامي العام، بتأييدا الحل الثاني لأن خدمة الوسـاطة المقدمة من جاتب المنصات الرقمية تسهم في خدمـة شاملة عنصرها الرئيسي هو خدمة النقل. 
عدد خاص بالمؤتمر الدولى السنوى العشرون أ.د / محمد محمد عبد اللطيف

وهذه الخدمـة الشـاملة تششكل جـزعاً مـن مسسئولية المنـصة الرقميـة إذا تـوافر شرطان:

الشرط الأول هو أنـهـ يجب أن تنشئ المنـصة أداء خدمـة لـم تكن موجـودة،

وليس مجرد أن تثكل وسيلة إضافية لتدعيم او توزيع خدمة موجودة من قبل بمعنى ان

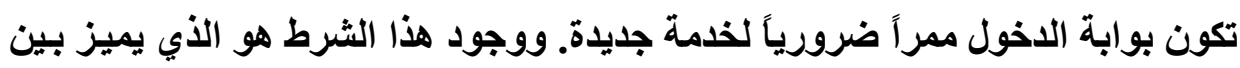

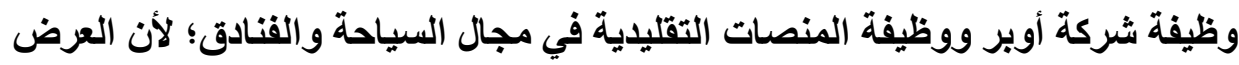
في الحالة الأخيرة يوجد استقلالاً عن المنصة الرقمية، وتختلف خصائص الخدمـة وفقاً لمقدم الخدمة، وتعد المنصة واحدة من عدة وسائل لتعزيز نشاط مقدم الخدمة.

وأمسا الشرط الثاني فهو أنـه يجب أن تمسارس المنـصة تـأثيراً حاسـماً على

أوضاع تقايم الخدمة. وقد اعتنفت المحكمة فكرة أن شركة أوبر تنظم خصائص الخدمـة

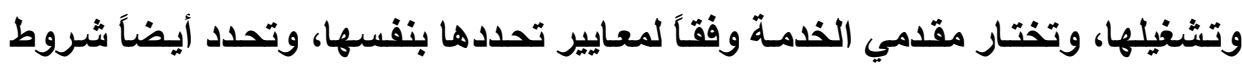
تقديم الخدمة بما في ذلك السعر الأي تحصل عليه ثم تدفع جزعاً منه للسائقين، وتراقب جودة الخدمة من خلال وظيفة التقييم، وأخيراً تحتفظ لنفسها بالاستبعاد من المنصة الرقمية السائقين الذين تراهم غير مناسبين.

وقد خلصت المحكمة من بتطبيق هذين الثرطين على أوبر أن خدمة الوسـاطة

التي تقدمها تعتبر جزءاً لا يتجزء من الخدمة الثـاملة التي تثكل خدمـة النقل عنصرها

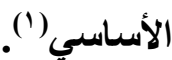

(1) V.Hatzopoulos, La première prise de position de la Cour en matière d'économie collaborative, note CJUE , 20 déc.2017, aff. C-434/15, Asociacion Profesional Elite Taxi c/ Uber Systems Spain SL, EU :C :2017 :981, RTD Eur, 2018, p.273; AJDA 2018. 329, chron. P. Bonneville, E. Broussy, H. Cassagnabère et C. Gänser ; RTD eur. 2018. 147, obs. L. Gran. 
عـرف تقـين النقل في فرنسـا النقـل بالسسيارات Le covoiturage هـو الاستخدام المشترك لمركبة من قبل سـائق وراكب واحد أو أكثر، ويتم إجراؤه مجانـاً ، باستثناء تقاسم التكاليف،في إطار رحلة يقوم بها السائق لحسابه الخاص، ووضعهم في اتصال لهذا الغرض يكون بمقابل(المـادة L.3132-1). وقد استهدف القانون الخـاص بالتنقل في ؟ Y من ديسمبر تشجيع هذا النوع من النقل؛ من أجل الحد من إطلاق غـاز الكربون في قطاع النقل مثل منح أماكن انتظار على الطرق العامـة سواءً بصفة مؤقتـة أو دائمة لمركبات النقل، وفرض التزام على المشروعات التي تستخدم خمسين عاملاً على ألأقل في موقع واحد باتخاذ تدابير لتحسين انتقال العمال من مكان الإقامـة المعتـاد إلى مقر العمل ومنها اللجوء إلى النقل الجماعي.

والعلاقة بين السائق والركاب هى بطبيعة الحسال عقد نقل مـادام العقد بمقابل. غير أن هذا المقابل ينبغي تحديده.وفقاً للقانون الفرنسي لايجوز للسائق أن يبحث عن أى ربح، ومن ثم لايلزم الراكب إلا باقتسام تكاليف الوقود ، ورسوم المرور.

وفي إطار هذا النوع من الاقتصاد التعاوني لايعتبر قائد المركبة سـائقاً مهنياً،

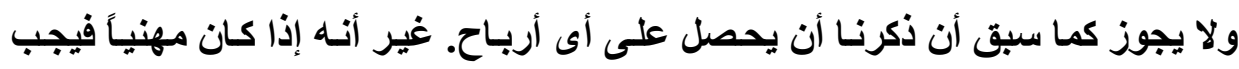

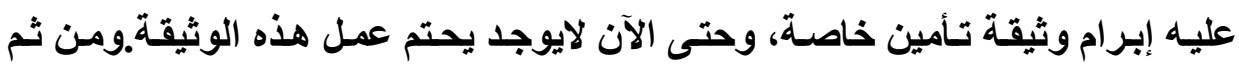

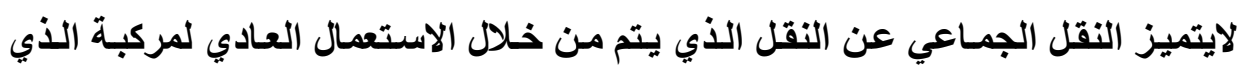
يسمح بنقل مرافق أو صديق أو زميل، وفيه لايلتزم السائق بإبرام وثيقة تأمين إضافية. وهذا النوع من الاقتصاد التعاوني لايفلت من نطاق القانون، ويخضع في حسال وقوع حادث لأحكام المسئولية المدنية للسيارات التـي تلزم قائد المركبة بإبرام عقد تـأمين سيار ات حتى يتمكن من الانتقال بالمركبة. 
عدد خاص بالمؤتمر الدولى السنوى العشرون أ.د / محمد محمد عبد اللطيف

ومن البدهي أن النقل المشترك بالسيارات على هذا النحو يفترق عن خدمات النقل التي تقترحها منصات أخرى مثل Auber التي تقوم بالنقل بمقابل.

وعلى غرار النقل المشترك بالسيارات يوجد أيضاً النقل المشترك بالطائرات

coavinnage Le طائرة خاص، على أن تثم هذه العمليات عبر منصة إليكترونية تضع القائد والركاب في علاقة قاتونية.

وخلافاً للنقل المشترك بالسيارات، توجد اعتراضـات من جانب إدارة الطيران

المدني على النقل المشترك بالطائرات مرجعها أسباب متعلقة بـالأمن، ووضعت قيوداً مشددة على هذا النقل.وألغى مجلس الاولة قراراً لهذه الإدارة بتنظيم النقل المشترك بالطائرات؛ استناداً إلى عدم وجود مخاطر متزايدة على الأمن ترتبط بتطور نشاط النقل المشترك بالطائرات الأي تنظمه منصات إليكترونية عبر الإنترنت، وهو مـا أسـهم في انتعـاش هـا النـوع مـن النقـل(') ، مـع مراعـاة احترام قواعد التـي فرضـتها الوكالــة الأوروبية للسلامة الجوية خصوصاً ميثاث سـلامة الرحلات غير التجاريـة في الطيران الخفيف الذي وقعته المنصات الرقمية للطيران المشترك في V V ـ ץ(؟).

(1)CE,22 juin 2017, n.404619 ; AJDA, 2017, p.1814; Juris tourisme $\mathrm{n}^{\circ}$ 200/2017, p. 13, obs. X.Deplech.

(2)X.Delpech, Le coavionnage, une activité en devenir, Juris tourisme,2017, n.202, p.27. 
عدد خاص بالمؤتمر الدولى السنوى العشرون أ.د / محمد محمد عبد اللطيف 
عدد خاص بالمؤتمر الدولى السنوى العشرون أ.د / محمد محمد عبد اللطيف

\section{المبحث الثاني}

\section{تنظيم الاقتصاد الزقمي}

دائماً ما يثار التساؤل عن إمكانيـة تنظيم الاقتصاد الرقمي بشكل عـام (المطلب الأول)، وإخضاعه للنظام الضريبي بوجه خاص(المطلب الثاني).

\section{الاطبا الأول}

\section{التننظيم القانوني للاقتصاد الرقمي}

يتجـه الاقتصاد الرقمسي إلى تركز الأسـواق؛ بسبب العائـدات المتزايدة.وتبـو

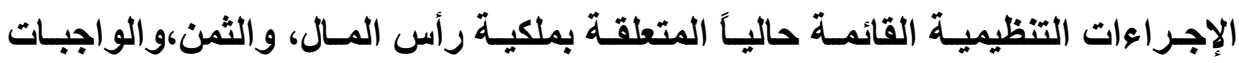
المفروضة على سلوكيات المشروعات غير متلائمسة مـع المشروعات المسيطرة على الإسى الاقتصاد الرقمي التي تستمد فعاليتها من إعمال آثار الشبكات ؛ بفضل رفع الحواجز على الاخول في أسواقها. شروط الاخول في الأسواق للمنصات الرقمية:

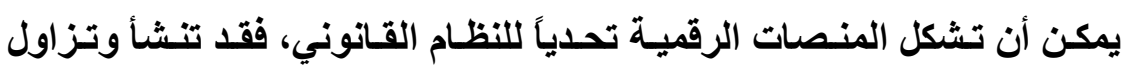
نشاطها دون أن تتو افر فيها الثروط التي يحددها القانون، ويظل نشاطها غير مشروع

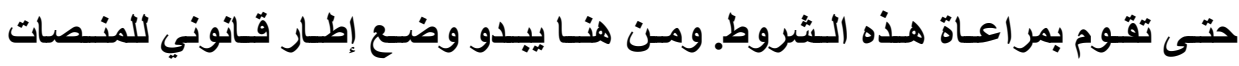
الإليكترونية أمراً ضرورياً بعد أن أصبحت لاعباً مهماً في الحياة الاقتصادية)(')

(1)I.Parachekevova et M.Teller, Quelles régulations pour l'économie collaborative ? Dalloz, 2018. 
عدد خاص بالمؤتمر الدولى السنوى العشرون أ.د / محمد محمد عبد اللطيف

وقد واجهت دول عديدة أوروبية وغير أوروبية هذا الفرض بمناسبة الاتتشار السربع للمنصة الأمريكية الشهيرة Uber التي بدأت أنثطتها في خدمة نقل الأشخاص بالمخالفة لقوانين المرور التي تشترط لممارسـة هذا النشاط أن يتم بواسطة سيارة أجرة، وليس بواسطة سيارة خاصة مزودة بسائق.

وفي مصر، واستناداً إلى هذا السبب، قضت محكمة القضاء الإداري في • r من

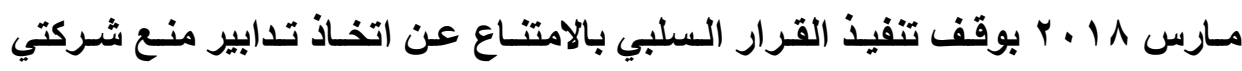

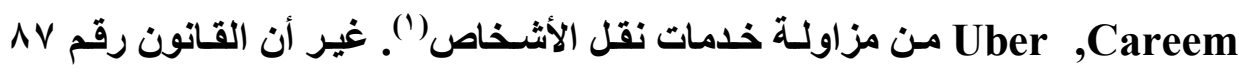

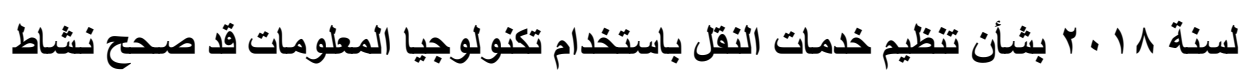
هاتين الثركتين من خلال تنظيمه لأول مرة ، ومن ثم أصبح مشروعاً (؟)، الأمر الذي باتي

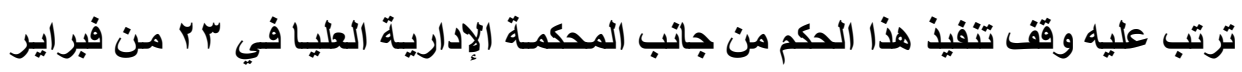
(r) $r .19$

وما يزال الاقتصاد التعاوني للمنصات الرقمية محلاً للار اسـات. فقد رأى تقرير لمجلس الشيوخ الفرنسي أن هذا النوع من الاقتصاد يؤدي إلى خسائر ضريبية للاولة ، ويشكل منافسة غير نزيهة مع المشروعات التقليليـة التي تتدخل في نفس القطاعـات، وإذا كانت المنافسة مـع نمـاذج اقتصادية أخرى جديدة مشروعة، غير أن ذلك يكون بشرط خضوعها لنفس الثروط والقواعد الضريبية (؛).

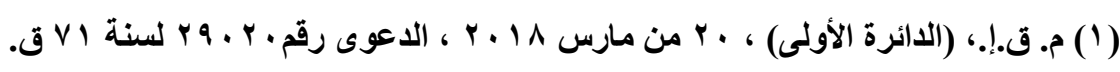

(2) M.Vivant, $L$ 'art très remarquable de viser faux , D., 2018 , p.2017.

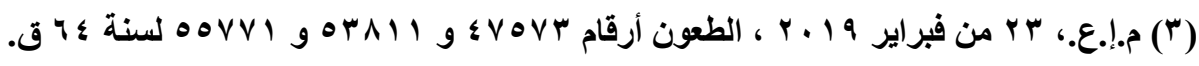

(4) X.Delpech, Fiscalité -Taxe de séjour-Pour une fiscalisation douce de l'économie collaborative, Juris tourisme 2015, n.179,p.10. 
عدد خاص بالمؤتمر الدولى السنوى العشرون أ.د / محمد محمد عبد اللطيف

وتثير الأنشطة المتنوعة للمنصات الرقمية على النحو الذي عرضناه عمومـاً التساؤل عن مدى إمكانية تنظيمها. غير أن الإجابة عن هذا التساؤل لم تكن حتى الآن محلاً للاتفاق على مستوى الاتحاد الأوروبي. وبصفة عامة توجد ثلاثة اقتراحات.

أمسا الاقتـراح الأول فهو وضـع إطـار قـانوني عـام تخضع لـه جميع المنصات الإليكترونية.وهذا الاقتراح لم يلق تأييداً واسعاً:كأنه من الصعوبة وضع نظعام قانوني تخضع له جميع الأطراف، بالإضافة إلى أن التدخل من خلال التدابير التظظيمية لا يكون إلا لمعالجة مشكلات محددة تتعلق بنوع محدد من النشاط. وأما الاقتراح الثاني فيرى أنـه بـلاً من وضـع إطـار قانوني يطبق على جميع

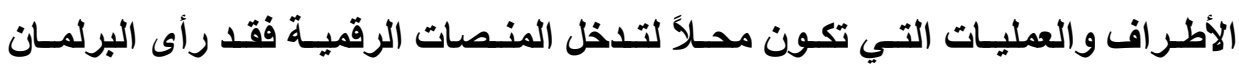
الأوروبي التركيز على بعض الأنشطة والمشكلات الخاصة التي يمكن أن تكون محلاً لتنظيم خاص.

وأخيـراً انتهـت اللجنــة الأوروبيـة إلــى اقتـراح آخـر يطلـق عليـهـ التنظـيم السلبي، ومؤداه تحديد تأثير الأدوات القانونية القائمة على أطراف الاقتصاد التعاوني، وذلـك قبـل إقـرار تعليمـات بتفسير هـذه الأدوات في هـذا السياق؛ ومـن ثـم تنـــاز اللجنـة إلى تعليمـات محددة تصاحب تطبيق النصوص الحاليـة على أطراف الاقتصاد

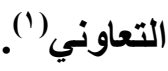

(1) P.Van Cleynenbreugel, Le droit de l'Union européenne face à l'économie collaborative, précité . 
عدد خاص بالمؤتمر الدولى السنوى العشرون أ.د / محمد محمد عبد اللطيف

وهذه المشكلة تواجـه على الأرجـح مختلف الدول، ويبدو الحل الثاني الأكثر

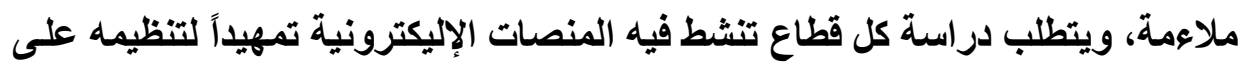
نحو ما تم في دول عديدة بالنسبة لمنصة شركة أوبر. الاقتصاد الرقمي وقانون المنافسة:

التظيم القانوني للاقتصاد التعاوني للمنصات الرقمية ليس كاملاً. وعلى سييل

المثال وعلى الرغم من أن هذه المنصات يمكن أن تلعب دوراً سابقاً على التعاقد أو دوراً

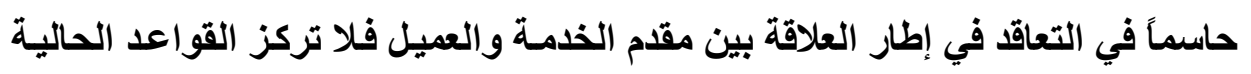

على الممارسات التجارية غير النزيهة أو على مسئولية المنصات الإليكترونية (1). ويظل قانون المنافسة غير مطبق بشكل أو آخر على الاقتصاد الرقمي، فمن

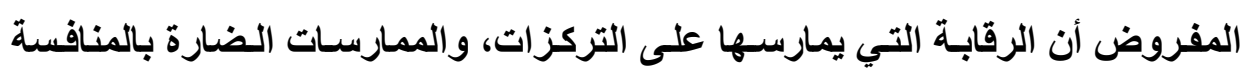
يؤدي إلى إقامة سوق تنافسي سليم لمصلحة المستهلكين.ومع ذلك لاتوجد صعوبة في ملاحظة أن قانون المنافسة لا يطبق بشكل واسع على الاقتصاد الرقمي، ولم يتمكن من وقف هيمنة المشروعات العملاقة مثل جوجل.

ومع ذلك توجد بعض تطبيقات لقانون المنافسة في الاقتصاد الرقمي(؟). ا ـ تطبيق قانون المنافسة في مجال الاحول على قواعد البيانات:

أصبح الاخول على قواعد البيانـات واستخدامها عناصر أساسية في الاقتصاد الرقمي، واعتبر القضاء أن رفض الـخول يمكن أن يشكل إسـاءة لوضع مسيطر.فقد

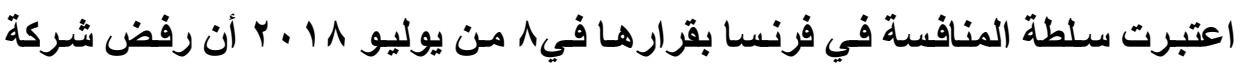

(1) J.Senechal, Ubérisation et droit de la consommation, D.2017, p.363 .

(2)N.Malvert, Le droit de la concurrence à l'épreuve de l'économie numérique, Mémoire, Paris I, Sorbonne, 2016/2017.

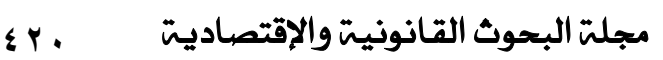


عدد خاص بالمؤتمر الدولى السنوى العشرون أ.د / محمد محمد عبد اللطيف

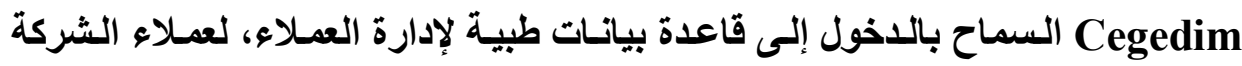

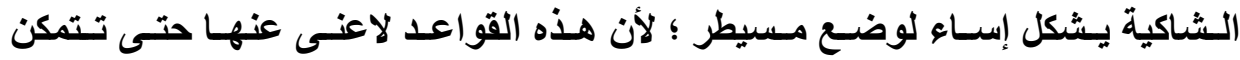

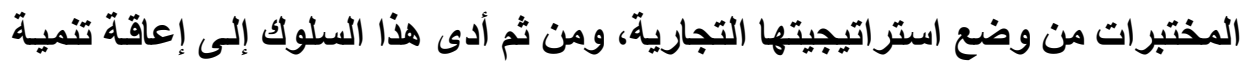
الثركة الثاكية في السوق ودفع برحيل عدد من عملائها.

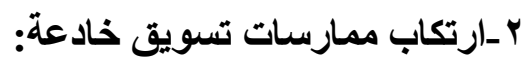

وجد هذا النوع من الممارسات تطبيقًا في حالة شركة UberPop التي تعمل في مجال نقل الأشخاص بمقابل على سيار اتها الخاصة. و التطبيق كان سئل التهل الاستخدام بالنسبة للمستخدمين الذين يعرفون تعريفة الركوب. وأعلنت الشركة عن تطوير كبير

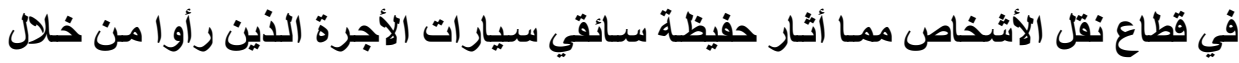

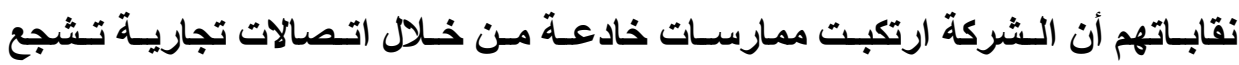

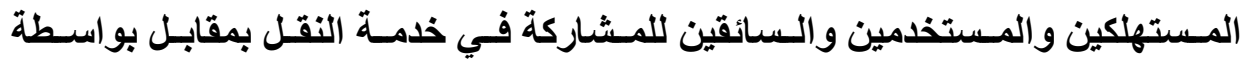
العاملين في الثركة، مما يعطي الانطباع بأن هذه الخدمة مشروعة ، بينما هى ليست كنلك وفقاً لتقتين الاستهلاك.

وقد ألغت محكمة الاستيناف جزئياً حكم محكمة أول درجة، مع اعتبار الشركة

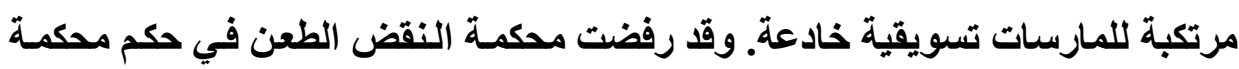

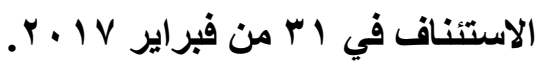

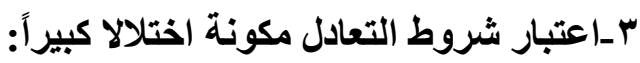

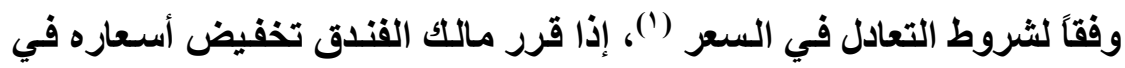

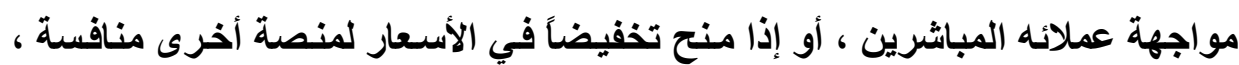
(1) « Clauses de parité ». 
عدد خاص بالمؤتمر الدولى السنوى العشرون أ.د / محمد محمد عبد اللطيف

فيجب أيضاً أن يفيد منه المنصة المتعقد معها ؛ لأنه لايصح أن يكون أكثر فائدة للعميل النهائي حجز ليلته من خلال الاتصال المباشر بالقندق، وليس من خلال المنصة. واعتبرت المحاكم أن شرط التعادل المبرم بين المنصات الإليكترونية والقنـادق يشكل اختلالا كبيراً استناداً إلى نصوص تقتين التجـارة، وقضت ببطلانه، بـالنظر إلى عدم وجود مقابل كافٍ للالتزام بالتعادل من جاتب المنصة الإليكترونية. واعتبرت سـلطة المنافسة أيضاً أن شروط التعـادل المتعلقة بالسعر والإتاحة تحرم الفندق من دعامتين يعتمد عليهمـا مستوى سـر التجزئـة وعدد الليالي المؤجرة للتعامل مع أسعار العمولة التي تتقاضـاها منصة الحجز، وأن هذه الشروط تؤدي إلى الحد من المتافسة بين وكـالات السفر عبر الإنترنت، وتنطوي على مخـاطر باستبعاد المنصات الضغيرة و المنصات الجديدة الصاعدة" (1) وقد أدانت محكمة النقض أيضاً في فرنسا إحدى الشركات العملاقة في مجال الحجز (†)؛استناداً إلى ارتكاب ممارسـات مقيدة للمنافسة؛ ومن ثم أيدات إلغاء بعض الشروط التي فرضتها على الفنادق المنضمة إلى منصتها بسبب مـا تضنته من اختلال كبير (r). جهود الاتحاد الأوروبي في تنظيم الاقتصاد الرقمي:

(1) Aut. conc., 21 avr. 2015, $\mathrm{n}^{\circ}$ 15-D-06, D. 2016. 964, obs. D. Ferrier; JT 2015, $\mathbf{n}^{\circ} 175$, p. 8, obs. S. Zouag; ibid., $n^{\circ} 176$, p. 11, obs. X. Delpech. S.Atsarias-Dumas, Le contrôle du contrat par l'Autorité de la concurrence, AJ Contrat,2020,p.474.

(2) « Booking.com».

(3) Com. 8 juill. 2020, $\mathrm{n}^{\circ}$ 17-31.536, Juris tourisme 2020, $\mathrm{n}^{\circ}$ 233, p. 11, obs X.Delpech . 
عدد خاص بالمؤتمر الدولى السنوى العشرون أ.د / محمد محمد عبد اللطيف

تتجه جهود الاتحاد الأوروبي إلى وضع نظام تشريعي للاقتصاد الرقمي، انطلاقًا من مجموعتين من الاعتبار ات:

أمسا المجموعة الأولى فترجع إلى صعود مشروعات عملاقة في المجـال الرقمي تتو افر لايها خصائص جديدة وخاصة بها. وتفرض المنصات الكبرى مشكلات كبيرة ناشـئة من حجمها ونطاقها عابر للحدود الوطنيـة، وبوجه خـاص من نمـوذج الأعمـال الأي تتميز به الذي يخلط أسواقاً متنوعة، والاخول عبر الإنترنت في تطبيقات خاصة، والاستغلال الكثيف للمعلومات.

وأمـا المجموعـة الثانيـة مـن الاعتبـارات فتكمن في أن السلطات المعنيـة في الاتحـاد الأوروبـي تعتـرف بـأن الأدوات التـي تحـت ســلطاتها ليست كافيـة لمعالجـة المشكلات التي تثيرها هذه المشروعات.فالغرامات ومختلف الجزاءات الموقعة لم تؤد إلى تلدعيم المنافسة في هذه الأسواق، كمـا ان أدوات التظيم الحالية التي تتمثل في

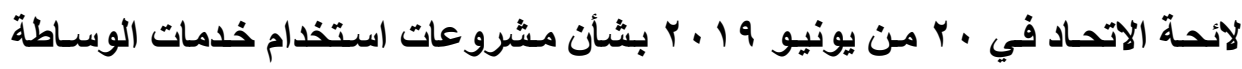
عبر الإنترنت بلت بدورها غير كافية. وتعكف اللجنة الأوروبية على وضع إطار تنظيمي للاقتصاد الرقمي، وقد نشرث

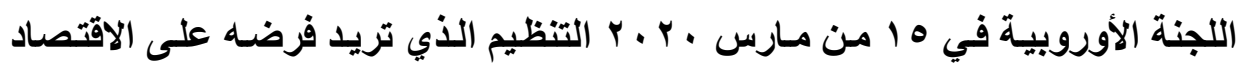

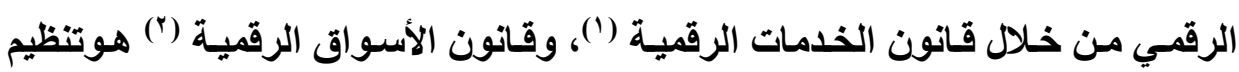
المنصات الرقمية مثل شبكات التواصل الاجتمـاعي، ومنصات المشاركة في المحتوى، ومنصات الأسـواق عبر الإنترنت، ومحركـات البحث مثل جوجل. والهدف هو تقرير مسئولية هذه المنصات، خصوصاً بشأن دورها الضروري في مكافحة نشر محتويـات

(1) Le « Digital Service Act ». (DSA)

(2) Le « Digital Market Act ». (DMA)

مجلتّ البحوث القانونيت والإقتصاديت 
عدد خاص بالمؤتمر الدولى السنوى العشرون أ.د / محمد محمد عبد اللطيف

غير مشروعة أو ضارة ، وسلوكياتها في الأسـواق؛ حتى يمكن منـع ممارسـات التحكم في الأسواق ومعوقات الإباع، وتنمية العروض البديلة.

ويفرض مشروعا القانونين قواعد جديدة من أجل منـع المنصات الكبرى من

التحكم في الأسواق، وفرض شروط تجارية أو تقنية غير عادلة.كمـا تتنـاول أيضاً إلزام المنصات الإليكترونيـة بالاستعانة بالوسـائل الضرورية لمكافحة نشر المحتويـات غير المشروعة عبر الإنترنت ، أو الضارة بلمستخدمين. وعلى المنصات الإليكترونية إثبات

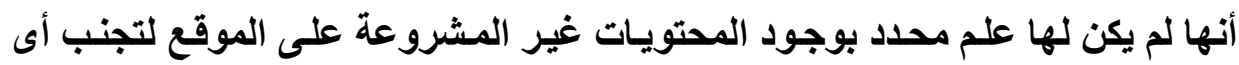
مسئولية، أو إثبات أنها تصرفت بسرعة من أجل إزالة أو عدم تفعيل الوصول غلى هذه

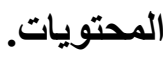

وتطبق هذه المقترحة على الثبكات الاجتماعية، والأسـواق عبر الإنترنت أو

منصات البيع الكبيرة عبر الإنترنت، ومنصات مشاركة المحتوى.غير أنها تطبق على المنصات الكبرى وفقاً لعدة معايير منها:الحجم taille ، وعدد العمـلاء، ورقم الأعمـال

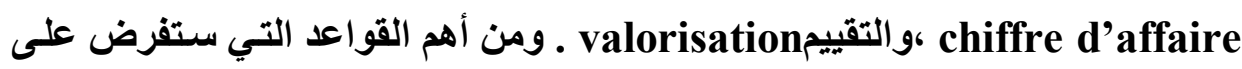
المنـصات الكبرى إلزامها بالإخطـار المسبق عـن أى اسـتحواذات جديـدة ، وتطبيـق . الشفافية فيما يتعلق بالإعلانات على المنصات.

\section{الاطلب الثاني}

\section{النظام الضريبي للاقتصاد الرقمي}

النظام الضريبي للمنصات الرقمية:

من الملاحظ أن الاقتصاد التعاوني ينمو بعيداً عن النظام الضريبي، ويؤدي إلى خسائر في إيرادات الدولة، كما يشكل منافسة غير مشروعة للمشروعات التقليدية التي تتدخل في نفس القطاعات. و إذا كاتت منافسة نمـاذج اقتصادية جديدة تكون جائزة، إلا 
عدد خاص بالمؤتمر الدولى السنوى العشرون أ.د / محمد محمد عبد اللطيف

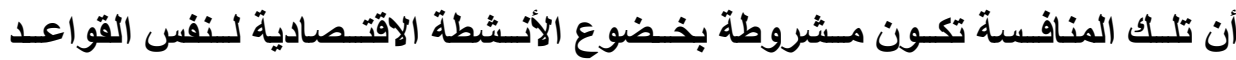
الضريبية (1)

يـضاف إلسى ذلـك عـدم تـوطين non-localisation يسـهم فيطمس الحـدود

الجغرافيـة والماليـة، واللدور الكبيـر الـذي تلعبـه المنـصات الرقميـة، وأخيراً اسـتغلال البياتـات الثخصية في اقتراح تقديم خدمات شخصية غالبـاً مساتكون مجانية ويمكن

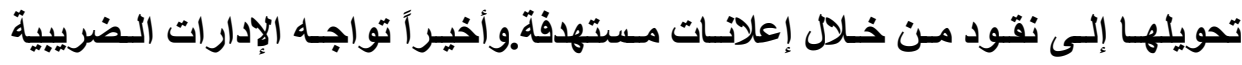
صعوبات في تعديد الإقليم المعني بالإنتاج.

ومـع ذلكك توجد روئة أخرى مفادهـا أنـه مـن الأفضل تكييف الضرائب على

الاقتصـاد التعـاوني، وأن وضـع إطـار لـه ينبغـي أن يتم مـن خـلال وضـع نظـام ضـريبي واجتمـاعي عام يطبق على جميع المنصات والمستخدمين، ويقوم على ثلاثة مبادئ

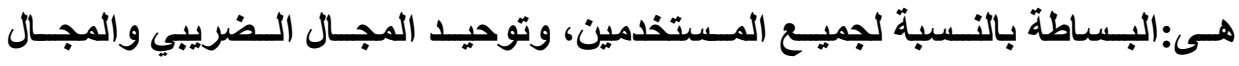
الاجتمـاعي، والعدالة بين الممولين من دون منافسة غير مشروعة. وقد قدمت لجنـة المالية بمجلس الشيوخ تقريراً تتضمن اقتراحات تفصلية للنظام الضريبي للمنصات

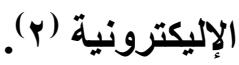

وتطبق القواعد العامة على الاقتصاد التعاوني للمنصات الرقمية. ومن مظاهر تطبيق هذه القواعد أنها تخضع للضرائب على الاخل أو الثركات، هذا من ناحية. ومن ناحية أخرى ومن حيث المبدأ تخضع للضر ائب اللاخول الناتجة للأفر اد من ممارسـة

(1)X.Deplech, Fiscalité -Taxe de séjour-Pour une fiscalisation douce de l'économie collaborative, Juris tourisme,2015, n.179, p.10.

(2) X.Deplech, Fiscal -Impôt-Vers une nouvelle fiscalité pour l'économie collaborative, Juris tourisme, 2017, n.197,p.12 . 
عدد خاص بالمؤتمر الدولى السنوى العشرون أ.د / محمد محمد عبد اللطيف

أنشطة من أى نوع، بما في ذلك دخول الخدمات المؤداة لأفراد آخرين دخلوا سوياً في علاقة عبر وساطة منصات الاقتصاد التعاوني، فيما عدا الاخول الناتجة عن الاستهلاك المشترك الذي يعادل اقتسام التكاليف فلا تخضع للضرائب ('). وتضمن قانون بr من أكتوبر 1 | • ب في فرنساً نوعين من الأحكام التي ترمي

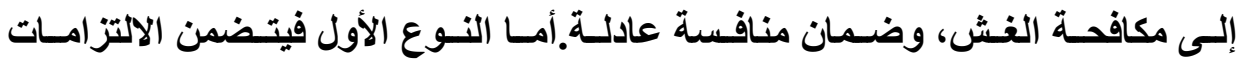
الضريبية والاجتماعية المفروضة على منصات الاقتصاد التعاوني منها التزام المنصات بتقديم معلومـات كاملـة وسنوياً بشأن جميع المستخدمين للمنصة للإدارة الضريبية، ويؤدي عدم احترام هذا الالتزام إلى تطبيق غرامـة تعـادل ه \% من قيمة المبالغ غير

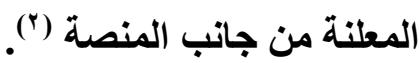
وأما النوع الثاني من الأحكام فهو إقامة المسئولية التضامنية للمنصات الرقمية لافع ضريبة القيمة المضافة TVAالمستحقة على البائعين الذين يمارسون أنشطتهم بواسطة هذه المنصات(")

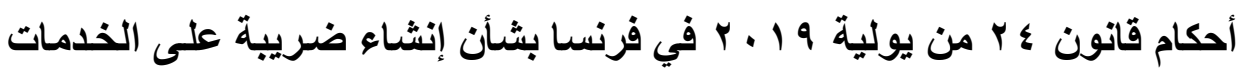

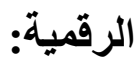

أصبحت فرنسـا إحـى الـدول القليلـة في أوروبـا التـي تفرض ضـريبة على

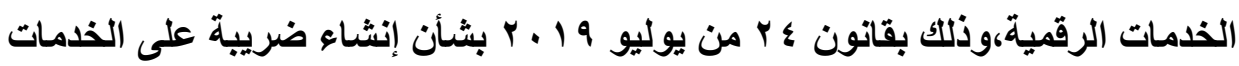

(1) X. Deplech, Fiscalité - Covoiturage - L'économie collaborative n'échappe pas toujours à l'impôt, Juris tourisme, 2016, n.190, p.11.

(2) E.Royer, A la une. Locations de courte durée. - Vers une meilleure régulation, Juris tourisme, 2018, n.208, p.6

(3) E.Royer, Economie collaborative-Pour une concurrence plus juste , Juris tourisme, 2018,n.214.p.8 


\section{عدد خاص بالمؤتمر الدولى السنوى العشرون أ.د / محمد محمد عبد اللطيف}

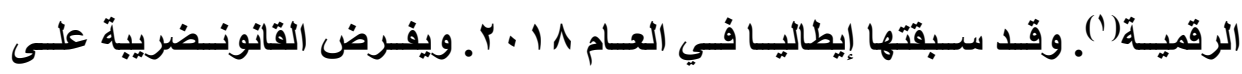
المشروعات الكبرى للقطــاع الرقمـي التـي تحصل على جزءعٍ كبير مسن دخولهـا مـن أنشطتها على الإقليم الوطني.

وهذه الضريبة تستلهم الاقتراح الذي تضمنه توجيه اللجنـة الأوروبيـة بشأن النظام المشترك للضريبة على الخدمات الرقميـة التي تطبق على العائدات من تقديم بعض الخدمات الرقمية. وهى تستجيب لضرورة حالة هى تحقيق العدالـة الضريبية في

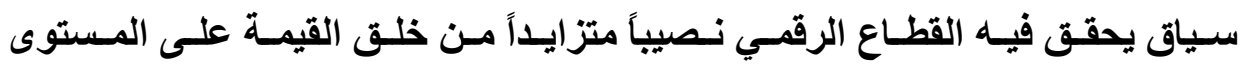

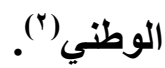

ووفقـاً للمسادة الأولـى مـن هـذا القـانون تفرض ضـريبة على أسـاس المبـالغ المحصلة من قبل مشروعات القطاع الرقمي مقابل التقديم في فرنسـا في خلال سنة

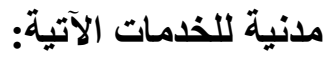

1 ـ تقديم واجهة رقمية عن طرق الاتصالات الإليكترونية تسمح للمستخدمين بالتواصل مع مستخدمين آخرين والتفاعل معهم؛ لاسيما بهذف تسليم بضائع أو تقديم خدمات

(1) Loi n.2019-759 du 24 juillet 2019 portant création d'une taxe sur les services numériques et modification de la trajectoire de baisse de l'impôt sur les sociétés.

(2) Etude d'impact, projet de loi portant création d'un taxe sur les services numériques et modification de la trajectoire de baisse de l'impôt sur les sociétés, p.6 et

https://www.legifrance.gouv.fr/contenu/Media/Files/autour-de-laloi/legislatif-et-reglementaire/etudes-d-impact-deslois/ei art 39 2019/ei ecoe1902865I pil taxe gafa et modification tra jectoire baisse impot societes $\mathrm{cm} \mathrm{6.03.2019.pdf}$ 
عدد خاص بالمؤتمر الدولى السنوى العشرون أ.د / محمد محمد عبد اللطيف

بصورة مباشرة بين هؤلاء المستخدمين، وذلك فيمـا عدا الاستثاعات التي حددتها

هذه المادة.

Y ـ الخدمات التي يتم تسويقها للمعلنين أو وكلائهم، وتهـف إلى وضع رسـائل إعلانية على واجهة رقمية بناءً على البيانات الخاصـة بالمستخدم الذي يعود إليها ، ويتم جمعها أو إنشاؤها بمناسبة الرجوع إلى هذه الواجهات، بمـا في ذلتك حينمـا يتم تنفيذها عن طريث الواجهات التي يستبعد توفير ها من الخدمات الخاضعة للضريبة. بـالواقعة المنشئة للضريبة تتكون بنهاية السنة المدنية التي قام في خلالها المشروع بتحصيل مبالغ مقابل تقديم خدمات خاضعة للضريبة في فرنسا. ومع ذلك وفي حالة توقف نشاط المدين بالضريبة تنشأ الواقعة المنشئة للضريبة عند حدوث هذا التوقف والمـدين بالـضريبة redevable هـو الـشخص الـذي يقـوم بتحـصيل المبالغ.وتصبح الضريبة مستحقة عند وقوع الواقعة المنشئة للضريبة. ع - وعاء الضريبة هو قيمـة المبالغ ، دون الضريبة على القيمـة المضافة، التي يـت تحصيلها بواسطة المدين بالضريبة، في خلال السنة التي تصبح فيها الضريبة مستحقة في مقابل خدمة خاضعة للضريبة مقدمة في فرنسا. هـ لاتخــع للـضريبة المنـصوص عليـه في القـانون التجـارة الإليكترونيـة، وتـوفير الخدمات الرقمية. צـ تخضع للضريبة على الخدمات الرقمية المشروعات الكبرى التي تتجاوز المبالغ

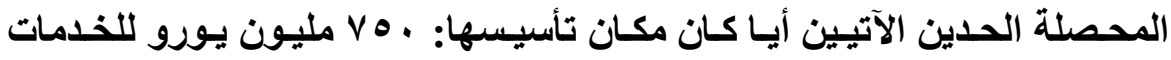

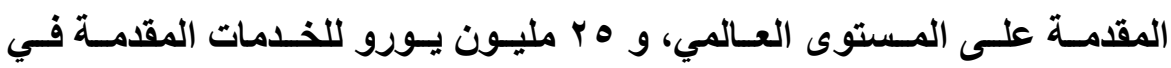
فرنسا.ويتم تقييم هذين الحدين على مستوى المجموعة التي تتكون من مشروعات 
عدد خاص بالمؤتمر الدولى السنوى العشرون أ.د / محمد محمد عبد اللطيف

المرتبطـة بعلاقـة رقابـة حصرية، وملزمـة بإنشاء حسابات موحدة وفقـاً لأحكـام

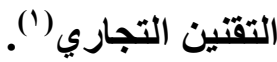

ويتوقع أن يطبق القـانون على مسا يقرب مسن · ب مجموعة مـن بينها جوجل

وأمازون وفيس بوك وأبل وانستجرام وغيرهـا. وهذا القانون لـه أثر وقتي إلى حين

التوصل إلى اتفاق دولي في إطار منظمة التعاون والتتمية الأوروبيةة(؟)وقد أطلق عيه أيضاً قانون GAFA نسبة إلى الحروف الأولى لأهم المشروعات التي ستخضع لـه

وهى : Google, Appel , Facebook, Amazon

وقد أثنار هذا القانون انتقادات سياسية مـن الولايـات المتحدة الأمريكية ، كمـا

توجـد أيضاً بعض التحفظـات القانونيـة مرجعهـا أن فرض الضريبة على طائفـة مـن

المشروعات من حجم معين وأغلبها مشروعات أجنبية يمكن ان يكون منطوياً على تمييز غير مباشر،استتاداً إلى مبدأ حرية تقديم الخدمات، ومساعدات الدولة وفقاً لقانون الاتحاد الأوروبي.وتوصلت الولايـات المتحدة الأمريكية وفرنسا في ج ب من أغسطس 9 1 • ب إلى اتفاق وافق بمقتضاه الرئيس الفرنسي على إعـادة النظر في الضريبة في حالة التوصل إلى حل بديل يتمثل في اتفاق دولي، ومن ثم يبدو مستقبل القانون غير إني

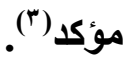

وقـــ رأى مجلس الدولـة أن المششروعات الخاضـعة للضريبة تمثل خصائص

تميزها عن المشروعات الأخرى، ومن ثم يقوم القانون في تحدي مجال تطبيقه على

(1) « Comptes consolidés »

(2) Adoption de la taxe « GAFA " par le Parlement, Légipresse, 2019, p.391.

(3)D.Gutmann, La « taxe GAFA » :quelques éléments d'analyse., 2019, p.1704 


عدد خاص بالمؤتمر الدولى السنوى العشرون أ.د / محمد محمد عبد اللطيف

معايير موضوعية لها علاقة مباشرة مع القانون. كمـا رأى المجلس أن اعتمـاد القانون على معيار للخضوع للضريبة مستمد من رقم الأعمال المرتفع بمـا يسمح بتقييم مـا إذا مونا كاتت المشروعات من تأثير المقياس اللازم لإقامة النموذج الاقتصادي هو استناد على معلى معادي

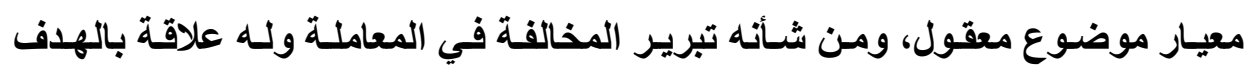

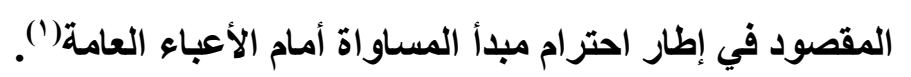

ولـم تـتم إحالـة القـانون الخـاص بشأن الضريبة على الخـدمات الرقميـة إلى لـ المجلس الاستوري لتقدير مدى مطابقته للاستور.

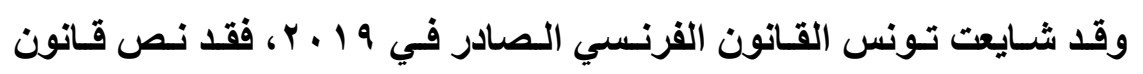

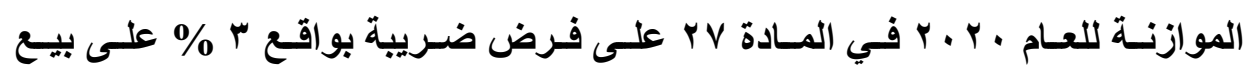
التطبيقات الإليكترونية والخدمات التي تقدم عبر شبكات الإنترنت من جانب الشركات الأجنبية التي لاتقيم في تونس().

(1) Conseil d'Etat, Avis sur un projet de loi portant création d'une taxe sur les services numériques et modification de la trajectoire de baisse de l'impôt sur les sociétés, p.4. https://www.conseil-etat.fr/ressources/avisaux-pouvoirs-publics/derniers-avis-publies/avis-sur-un-projet-de-loirelatif-a-la-creation-d-une-taxe-sur-les-services-numeriques-etmodification-de-la-trajectoire-de-baisse-de-l-impot-sur-l

(2)https://www.leaders.com.tn/article/28741-noureddine-friaa-loi-definances-2020-la-taxe-sur-les-services-numeriques-une-disposition-malconcue

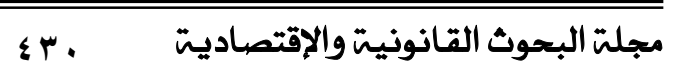


عدد خاص بالمؤتمر الدولى السنوى العشرون أ.د / محمد محمد عبد اللطيف

جهود الاتحاد الأوروبي مكافحة التهرب الضريبي للمنصات الرقمية:

يحسـاول الاتحسـاد الأوروبـي مـن جانبـه مكافــة التهـرب الـضريبي للمنـصات

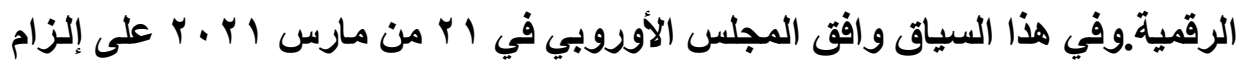
المنـصات الإليكترونيـة علـى تعـديل التوجيـه الاخــاص بـالتعون الإداري في المجـال الضريبي، وبموجب هذا التعديل يلتزم مشفلو المنصات الرقمية بـالإقرار عن اللاخول التي يحصل عليها البائعون على منصاتهم الإليكترونية، وتتبـادل الدول هذه المعلومـات

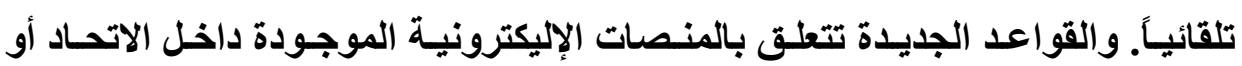

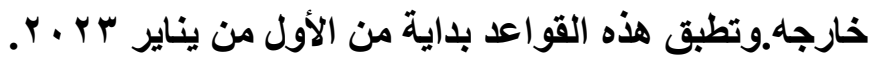

وبالإضافة إلى ذلك توجد مقترحات من اللجنة الأوروبية قدمتها في ديسمبر

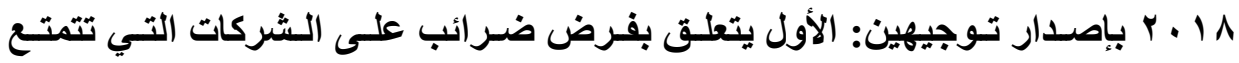
بحضور رقمي كبير، والثاني بفرض ضريبة على الخدمات الرقمية. 
عدد خاص بالمؤتمر الدولى السنوى العشرون أ.د / محمد محمد عبد اللطيف 
عدد خاص بالمؤتمر الدولى السنوى العشرون أ.د / محمد محمد عبد اللطيف

\section{المبحث الثالث}

العلاقات التعاقدية للاقتصاد الرقتمي

تنشأ عن الاقتصاد الرقمي عدة علاقات تأتي في مقدمتها العلاقة بين المنصة

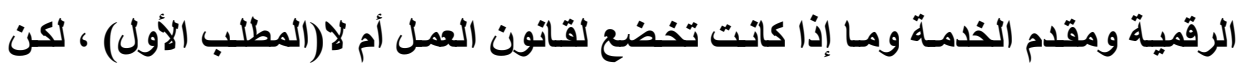
الاقتصاد الرقمي ينتج أنواعًا أخرى من العلاقات التعاقدية التي يجب تكييفها(المطلب الثاني)، وأخيراً يلقي المشرع بواجبات محددة على المنصات الرقمية، وترتبط هذه الواجبات بمسئولياتها فيي مواجهة العملاء(المطلب الثالث).

\section{المطاب الأول}

\section{الاتتصاد الرقمي وتطبيق قانون العهل}

مدى تطبيق قانون العمل في العلاقة بين المنصة الرقمية ومقدمي الخدمة: أثيرت في كثير من القضايا التي رفعها سائقون ومقدمو الخدمـة ضد المنصات الإليكترونية مسألة الاعتراف لهم بوصف العمال أو وصف المستقلين. وقد أعطى حكم محكمة العدل للاتحاد الأوروبي بعض الإثارات المهمة.

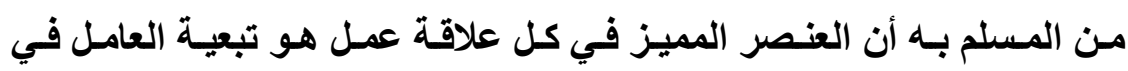

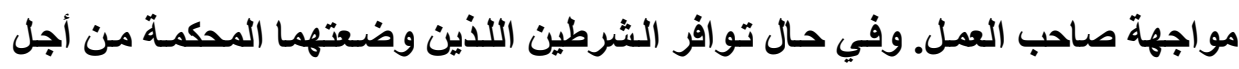

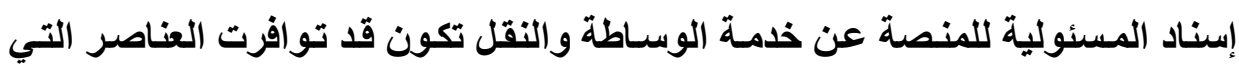
تبرهن على وجود علاقة التبعية.

ومع ذلك لا يجوز تعميم هذا الحكم في جميع الحالات. وعلى سبيل المثال ففي

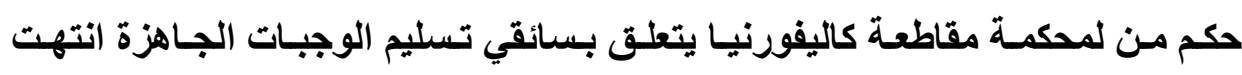


عدد خاص بالمؤتمر الدولى السنوى العشرون أ.د / محمد محمد عبد اللطيف

المحكمة انهم مقاولون مستقلون؛ استناداً إلى عدة أسباب منها أنهم غير خاضعين لأيسة

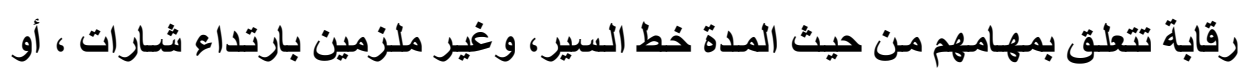

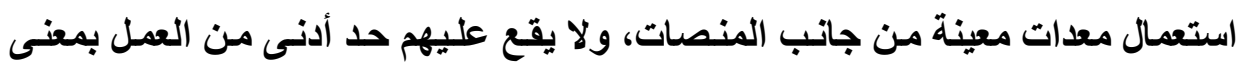
أنهم يختارون بحرية الساعات والأيام والأسـابيع التي يعملون في خلالها، يضاف إلى هـ ذلك أنهم لا يخضعون لرئيس أعلى في داخل المنصة، ولم يتلقوا أى تأهيل بواسطتها،

$$
\text { موثهم الحق في العمل مع أكثر من منصة( ). }
$$

وقد عرض على محكمة العدل للاتحاد الأوروبي مسألة ما إذا كانت منصة أوبر

هى مجرد منصة تقدم خدمات وسـاطة بين سـائقي المركبات والركساب، أم أنها على هلى العكس هى نفسها شركة نقل. وقد انتهت المحكمة ، مسايرة رأى المحامي العام ، بـأن أوبر شركة نقل، لأن الوسـاطة المقدمة من الشركة تسهم في خدمـة شـاملة عنصرها الأساسي هو نقل الركاب؛ لأنها تنشئ خدمة لم تكن موجودة من قبل،وتمسارس تـأثيراً حاســاً على شـروط الخدمـة ، ومسن مظـاهر هذا التأثير أنهـا تحدد خصائص وتقديم الخدمـة، وتختـار مقمدمي الخدمـة وفقاً لمعسيير تحددها، وتحدد شروط الخدمـة ومنهـا الثمن الذي تجمعه وتدفع جزعاً منه للسائقين، وتراقب تقديم الخدمـة من خلال وظيفة التقييم، وأخيراً يمكنهاأن تستبعد من المنصة السائقين الذين تقر أنهم غير مناسبين(ץ).

(1) Cite in V.Hatzopoulos, La première prise de position de la Cour en matière d'économie collaborative, précité.

(2) V.Hatzopoulos, La première prise de position de la Cour en matière d'économie collaborative, note ,CJUE,20 dec.2017, aff. C-434/15, Asociacion Profesional Elite Taxi c/ Uber Systems Spain SL, EU:C:2017:981, AJDA 2018. 329, chron. P. Bonneville, E. Broussy, H. Cassagnabère et C. Gänser; RTD eur. 2018. 147, obs. L. Grard 
عدد خاص بالمؤتمر الدولى السنوى العشرون أ.د / محمد محمد عبد اللطيف

ولم يختلف قضاء محكمة النقض في فرنسـا كثيراً عن قضاء محكمة العدل

للاتحاد الأوروبي وانتهت إلى أن العلاقة التي تربط بين شركة أوبر التي تستخدم منصة

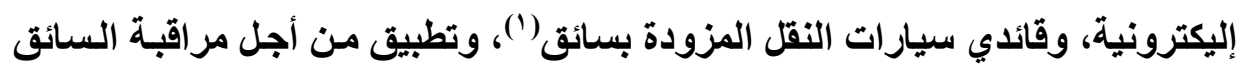

هى علاقة عمل تتميز بالتبعية.

وتستند المحكمة على أن علاقة التبعية تتميز بأن تنفيذ العمل يتم تحت سلطة

صاحب العمل الأي يتمتع بسلطة إصدار أوامر وتوجيهات، ومراقبة تنفيذها، وتوقيع جزاءات في حالـة مخالفتها، وأن العمل في داخل خدمـة منظمـة يمكن أن يعد مؤشـراً لعلاقة التبعية في الحالة التي يحدد فيها صـاحب العدل من جانب واحد شروط تنفيذ العمل. وقد رفضت محكمة النقض استبعاد هذا التعريف المستقر لعلاقة العمل وتبنـي معيار التبعية الاقتصادية الذي اقترحه بعض الفقه.

وانتهت المحكمة إلى تأييـ حكم محكمة الاستتنـاف التي خلصت إلى أن خدمـة

النقل أنشئِت ونظمت تماماً بواسطة الشركة، ولا توجد إلا بفضل المنصة الإليكترونية، وأن السائق ملزم باتباع طريق محدد، بل إن مكـان الوصول النهائي يكون في بعض لهض

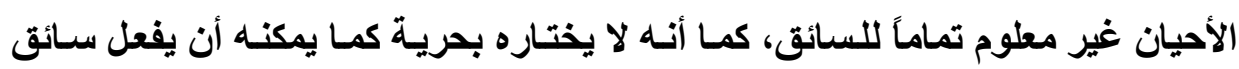

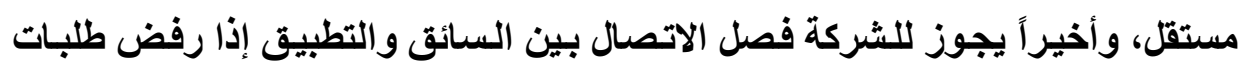
التوصيل ثلاث مرات. باختصار يخلص من هذه العناصر وجود علاقة تبعية عند اتصال سائق السيارة بتطبيق شركة أوبر.

(1) Conducteur de "voiture de transport avec chauffeur" (VTC) 
عدد خاص بالمؤتمر الدولى السنوى العشرون أ.د / محمد محمد عبد اللطيف

وانتهـت المحكمة أيضاً إلى أن مجرد احتفـاظ السائق بحريـة في اختيـار أيسام

وساعات العمل لا ينفي علاقة التبعية؛ لأن السائق بمجرد الاتصال بالمنصة ينضم إلى

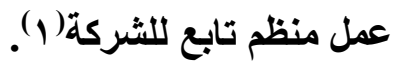

\section{الاطلب الثاني \\ العلاقات التعاقية للاقتصاد الرقهي}

تكييف العلاقات التعاقدية في الاقتصاد التعاوني:

يؤدي تـدل المنصات الإليكترونيـة إلى نشوء علاقـات تعاقديـة متعددة يطلق

عليها علاقات تعاقدية تعاونية(ץ). وعلى سبيل المثال إذا أراد مالكك سيارة تأجيرهـا عن طريـق منـصة إليكترونيـة يسـل نفسه في المنـصة ويقبـل شـروطها العامـة،وعلى المستأجر المحتمل للسيارة إجراء نفس الخطوات حتى يدخل في علاقة مع المالك ، وكل منهما يرتبط إذن بعقد مع المنصة في المرحلة الأولى. ويبرم كل من المالك والمستأجر عقد إيجـار السيارة وفي بعض الأحيـان تتـلـل المنصة في تحديـ الثمن والشروط. ويؤدي إبرام هذا العقد إلى دفـع مقابـل مـالي للمنصة، ثم إبرام وثيقـة تـأمين تغطي المستأجر في خلال مدة الإيجار،وإبرام عقد تأمين المدفوعات.وتتلدخل المنصة في أثناء تنفيذ العقد في حالة عدم الدفع أو عدم التففيذ.ويمكن ان يحدث هذا السيناريو بأشكال أخرى متنوعة.

(1) Cass.soc.,4 mars 2020, n.19-13.316, D.2020, p.490, Droit social, 2020, p.374, note P.-H.Antonmattei. ; Rev.de droit du travail ,2020, p.328, note L.Willocx ;

(2) « Relations contractuelles collaboratives ». 
عدد خاص بالمؤتمر الدولى السنوى العشرون أ.د / محمد محمد عبد اللطيف

وهذا السيناريو يثير التساؤل عن حقيقة العلاقـات التعاقدية المرتبطة بتدخل

المنصة الرقمية، وما إذا كان هذا التدخل يمكن أن ينعكس على العقود الأخرى(').

الرأى الأول: أحادية العقود:

يوجد رأى مؤداه أن العلاقات التعاقدية مهما تعددت هى في حقيقتها عقد واحد، فالمفاوضـات تتكون من عدة أدوات قد لا تتتهي جميعاً في وقت واحد.والأداة الأولى تتجسد في شكل الشروط العامـة، وأمـا الثانيـة فهى أداة الاستهلاكك التعـاوني، وإبرام الأخيرة يؤدي إلى إتمام العقد الذي من دونها يظل مجرد أعمال تمهيدية غير كافية لكي ينطبق عليها وصف أعمال تعاقدية.

وفقاً لهذه الروئة إذن نحن بصدد عملية قانونية واحدة من ثلاثة أشخاص تتميز

باتفـاق واحد ينشئ علاقـات قانونية منفصلة ومستقلة: الأولى منها بين الثخصين

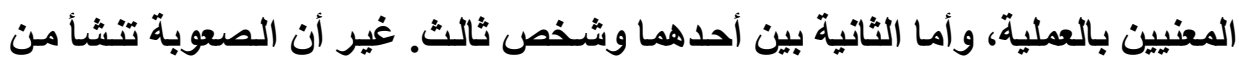
وجود ثلاثة عقود حسب الظاهر. فالعقد الأول بين مقدم الخدمة والمنصة، والثاني بين العميل والمنصة أيضاً، وأما الثالث بين مقدم الخدمة والعميل. وعلى ذلك نحن في حقيقة الأمر أمام ثلاثة أنواع من العلاقات التعاقدية.

ومع ذلك يرى أصحاب هذه الروئية أن تعدد العلاقات على هذا النحو لا يكفي لاستبعاد وحدة العملية التي يمكن تحليلها عبر مرحلتين: الأولى تتمثل في وجود اتفاقين تمهيديين يتمثلان في قبول الشروط العامة من جاتب مقدم الخدمة والعميل مع المنصة،

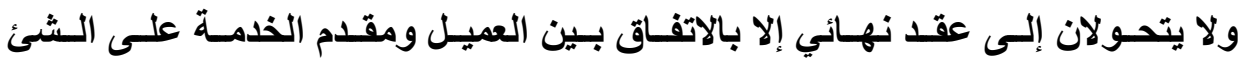

(1) A.Fortunato, La relation contractuelle collaborative , RTD com.2019 ,p.19. 
عدد خاص بالمؤتمر الدولى السنوى العشرون أ.د / محمد محمد عبد اللطيف

والخدمة.ومعنى ذلك أن الاتفاقين على قبول الثروط العامة لا ينتجـا أى أثر إلا بعد هذا العقد الأخير.

ومع ذلك ليس من المستبعد أن يحدث هذا القبول للشروط العامـة بعض الآثار مثل نقل بعض البيانات الشخصية، والتنازل عن حقوق الملكية الفكريـة، وقبول شروط المنصة، أو قبول طرق حل المنازعات الناشئة عن الثروط العامة.صحيح أن الانضمام إلى الثروط العامة ليس كافيًً للمشاركة في علاقة تعاقدية ، لكنه يؤدي إلى التزامـات تطبق مباشرة أو فوراً دون انتظار اتمام الاتفاق.ومن هنا يعد قبول الشروط العامـة في

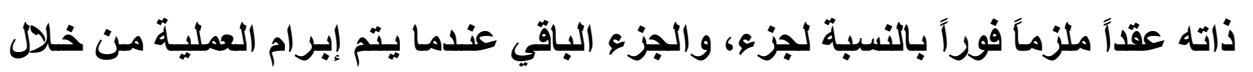
المنصة. غير أن العقد لا ينتهي بمجرد إبرام الاتفاق؛ لأن الشروط العامة ستطبق في كل

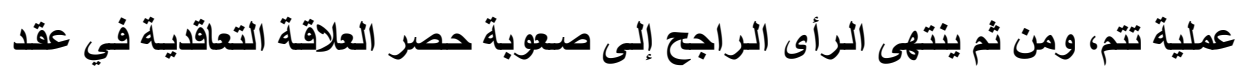
واحد أبرم بواسطة ثلاثة أشخاص. الرأي الثاني: تعددية العقود:

والرؤيسة الثانية تذهب إلى العكس إلى أنتـا بصدد عملية شـاملة( () تستتد من الناحية القانونية على ثلاثة عقود وإن كـان لها أن تجتمع معاً، وهى تشكل وحدة من العقود(ץ). إن تلخل المنصات الإليكترونيـة يؤدي إلى وجود عدة عقود حتى وإن كان يوجد بينها علاقة ارتباط، فالأمر في حقيقته هو عملية شاملة تستدعي عدة عقود بحيث يكون كل عقد ضرورياً وفي نفس الوقت لا يكون كافياً لإنجاز العملية.

(1) « Opération globale ».

(2) « Ensemble contractuel». 
عدد خاص بالمؤتمر الدولى السنوى العشرون أ.د / محمد محمد عبد اللطيف

إن الارتباط بين العقود يسمح بتوصيف علاقات التبعيـة المتبادلة لكل العملية

الشاملة، وأطرافها والعقود أيضاً.وقد استخدم الفقه فكرة السبب لوصف هذه العملية التي تثكل لهم السبب المشترك، أو اقتصادهم العام.واقتراح هذه الفكرة يعتبر طريقة؛ لأجل تجديد السبب.

ويخلص أصحاب هذا الرأى إلى أن هذه العملية التي تكوّن الاتفاق التعاوني ستجعل من الممكن توصيف علاقات الترابط بين هذه العقود الثثلاثة التي تم إبرامها لجعل العملية ممكنة. باختصار العقود الثثلاثة هى مكونـات عملية شـاملة التي لن تكون ممكنة دون أى واحد منها. وهذه العقود الثلاثة تشكل ما يسمى بالعملية التعاونية يمكن تحليلها على أنها عملية تتطلب إبرام عدة عقود أى وحدة من العقود. والعقود التي تثكل العملية التعاونية يمكن أن تكون في نهايـة الأمر جزعاً من العملية الشاملة التي يضاف إليها أيضاً عدداً من العقود التي يمكن وصفها بـالعقود الملحقة بمعنى أنها ليست لا غنى عنها لتنفيذ العملية.ومن هذه العقود عقود التأمين، أو عقود القرض.وهذه العقود يطلق عليها الفقه عقود تابعة من جاتب واحد، أو أنها عقود تكميلية (1).

والنتائج المترتبة على تكييف العلاقة التعاقدية بكونها وحدة من العقود يحكمها

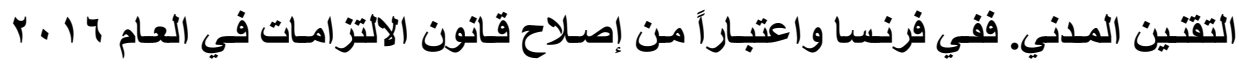
أصبحت تترتب نتائج خاصة على هذا النوع من العلاقات التعاقدية. ومن ثم يمكن أن يبرر زوال أحد العقود التي تستند إليها العلاقة التعاقدية إلى اعتبار العقود الأخرى كـأن لم تكن إذا أصبح تنفيذها مستحيلاً. وبالإضافة إلى ذلك يتم تفسير كل عقد من العقود

(1) A.Fortunato, La relation contractuelle collaborative , RTD com.2019, n.8 
عدد خاص بالمؤتمر الدولى السنوى العشرون أ.د / محمد محمد عبد اللطيف

المعنية وفقاً للعملية الثاملة، وهو مايسمح في إطار العلاقات القائمة بين العميل ومقدم

الخدمة أو المال بمجرد الإحالة إلى الشروط العامة للمنصة التي قبلها كل طرف (1).

وفيما يتعلق بمركز المنصة الرقمية في مواجهة العقد المبرم بين مقدم الخدمـة

أو المال والعميل تحرص مواقع هذه المنصات على تأكيد أنها من الغير في مواجهة هذا

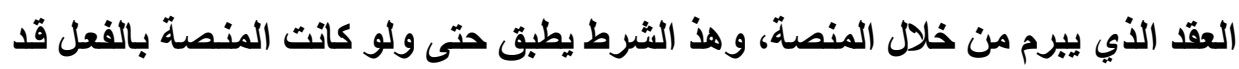

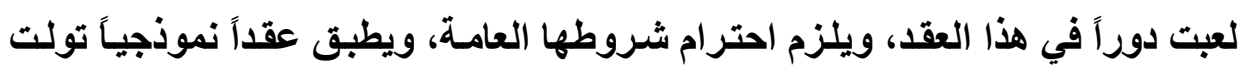
المنصة صياغته، وإجبارهم على اللجوء إليها عند عدم التنفيذ، أو بالاستفادة من إبرام هذا العقد بواسطة مقابل مالي.

ويميز قانون الالتزمـات دائمساً بين الأطر اف parties والغير tiers. وإذا كـان

مقدم الخدمة او المال يعتبر مع العميل طرفا العقد المبرم عن طريق المنصة؛ إلا أن دور الأخيرة يبدو صعباً إدراجه بسهولة في هذا التقسيم بين الأطراف والغير؛ بـالنظر إلى دوره الرئيسي واعتباره بمثابة الثخصية الرئيسية. ومن هنا عهر إليها البعض بمركز الطرف على مستوى العملية التعاقدية، وليس على مستوى كل عقد على حدة. ويرى آخرون أن المنصة من الغير غايـة الأمر أن العقد بين مقدم المـال أو الخدمـة والعميل يحتج به opposable العقد الثالث يتجاوز الغير لكنه يقع في وسط المسافة بين الطرف والغير، أو يكون مركز

(1) A.Fortunato, ,précité , n.16 .

(2) A.Fortunato, ,précité, n.12 .

مجلت البحوث القانونيت والإقتصاديت 
عدد خاص بالمؤتمر الدولى السنوى العشرون أ.د / محمد محمد عبد اللطيف

الاملب الثالث

واجبات المنصات الرقمية وهسئوليتها

واجب المنصات الرقمية في تقديم المعلومات:

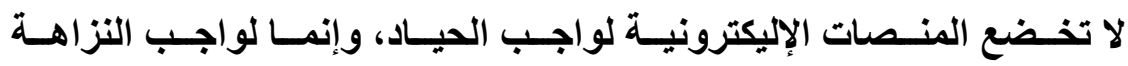

والوضوح' ()ومن ثم يوجب عليها القانون الكشف عن عدد من قواعد العمل للأفراد

بصفة عامـة ، وجميع مستخدمي المنصة،سواءً من المستهلكين أو المهنيين، مقدمي

الخدمات والأموال أو العملاء، وذلك في بـاب يكون متاحاً بسهولة ووضوح في جميع

صفحات الموقع.

وتخضع المنصات الإليكترونية لواجب تقديم المعلومـات. وقد نصت على هذا

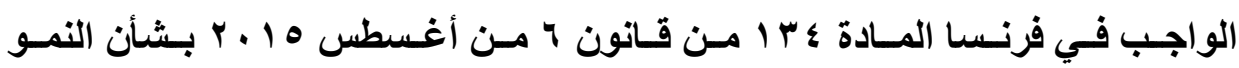

والأنشطة والمساواة في الفرض الاقتصادية التي أنشأت المادة L-115-5-1 من تقنين

الاستهلاك التي تناولت تقوية الالتزام بتقديم المعلومات المرتبطة بإقامسة علاقات رقمية

( $($ )

وتتص هذه المادة على أنه: يجب على كل شخص يتمثل نشاطه في وضع عدة

أطر اف في علاقات بالوسائل الإليكترونية؛ بهدف بيع سـلعة، او توريد خدمـة، او تبـادل

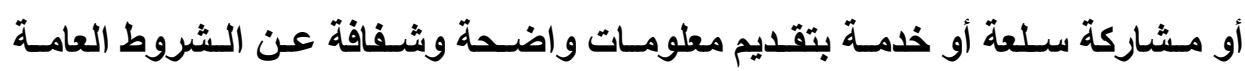

(1) J.Rochfeld et C.Zolyneski, La loyauté des plateformes, quelles plateformes ? quelle loyauté, D.2016,p.520.

(2) « mise $n$ en relation numérique » 
عدد خاص بالمؤتمر الدولى السنوى العشرون أ.د / محمد محمد عبد اللطيف

لاستخدام خدمة الوساطة، وبشأن شروط الإدراج والتصنيف وإلغاء إدراج العروض من

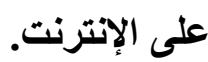

وفي حالـة مـا إذا كـان المستهلكون أو غيـر المهنيـين فقط هـم المقصودون

بالـاخول في العلاقـات فيجب على الشخص المشـار إليـه آنفاً تقديم معلومـات نزيهـة وواضحة وشفافة حول صفة المعلِن، وحقوق والتزامـات الأطراف في المسائل المدنية

والضريبية.

والمعلومات الوجوبية التي يجب على المنصة الإليكترونية تقديمها هى الثمن

الـذي تتقاضـاه المنـصة، وأن تحـد مـن يتحمـل الثمن أى مقـدم العرض أو الطالب،

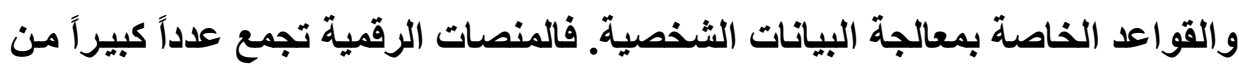
البيانات الثخصية، وتمنح نفسها حرية في استخدامها في غير أغراض المنصة مثل الأغراض التجارية دون تعويض المستخدم (1).

وأخيـراً ينبفي على المنـصات الإليكترونيـة الكشف على طريقـة الحوكمـة

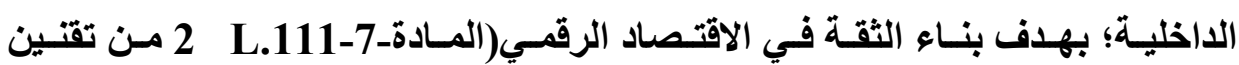

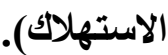

والإخلال بمختلف القواعد الخاصة بتقديم المعلومات يؤدي إلى توقيع الجزاعات المنصوص عليها في تقنين الاستهلاك في فرنسا.

(1) A.Bazot, Plateformes économie collaborative :des clauses litigieuses a deloger, Juris Tourisme, 2018,n.211,p.14 
عدد خاص بالمؤتمر الدولى السنوى العشرون أ.د / محمد محمد عبد اللطيف

مسئولية المنصات الإليكترونية:

القـانون المطبق على المنـصات الإليكترونية هو القـانون الخـاص بالثقة في

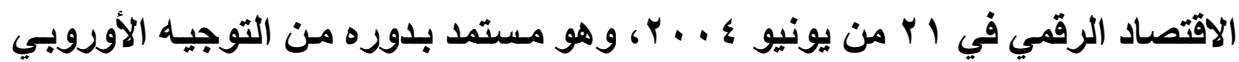

رقم اץ// . . . ب يثأن التجارة الإليكترونية.

ومسئولية المنصات الإليكترونية تختلف بحسب دورهـا الذي يمكن ان يكون

مزدوجاً؛ نظراً لأنها يمكن أن تكون وسيطاً تقتياً من بعد، أو مقدم خدمات للمستخدمين.

فبإذا كانـت المنصـات وسيطاً أو مـضيفاً hébergeur فقط للمـضمون الرقمي

فتخضع في هذه الحالة لنظام مسئولية مدنية وجنائية مخفقة عن المحتوى الأي وضعه على الإنترنت أحـد المستخدمين، ووفقـاً لـه لاتخضع للالتززام بـالتحقق مـن أن السلع والخدمات المعروضـة على الإنترنت تتفق مـع الإعلانـات الموضوعة والأداء المتوقع. وبعبارة اخرى لا تلتزم المنصات الإليكترونية بالتحقق من صحة المعلومات المقدمة من مقدمها، وإنما تسأل فقط عن نشر مضمون غير مشروع تعلم به(1). وبالمقابل تسأل المنصة الإليكترونية بوصفها مهنياً ترتبط بمستخدميها بعقد تقديم خدمات (ץ) الذي يختلف مضمونه ونطاقه من حالـة لأخرى. ومـع ذلك تخضع المنصة لواجب تقديم المعلومات، خصوصاً في مواجهة المستخدمين الأفراد. كمـا تسأل المنصات بثكل كامل عن حسن تنفيذ العقد الذي أبرمته مع المستخدمين(ب) الذي تطبق هوريق عليه قواعد قانون الاستهلاك.

(1) M.Peri ,La régulation de l"uberisation", D.IP/IT,2017,p.144.

(2) « contrat de prestation des services » (BtoC).

(3) Avis du Conseil national de la consommation sur les plateformes numériques collaboratives, Légipresse, 2016, p.236 
عدد خاص بالمؤتمر الدولى السنوى العشرون أ.د / محمد محمد عبد اللطيف

الخلاصــة

أصبح الاقتصاد التعاوني عبر المنصات الإليكترونيـة ، أو الاقتصاد الرقمي ، لاعبًا أساسيًً في الاقتصاد القومي ، وانتشر في مجالات كثيرة ، وبات حقيقة مؤكدة من حيث وجودها ودورها المؤثر.

المشكلة الرئيسية التي تبحث عنهـا اللدول هـ كيفيـة تنظيم هذا النـوع من الاقتصاد حتلى لا يظل بعيداً عن الاقتصاد الرسـي؛ حتى يخضع لرقابتها، ويـؤدي

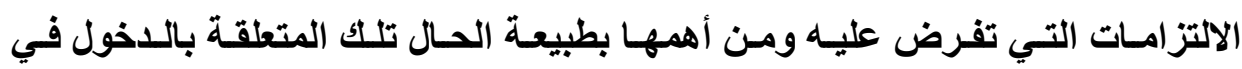

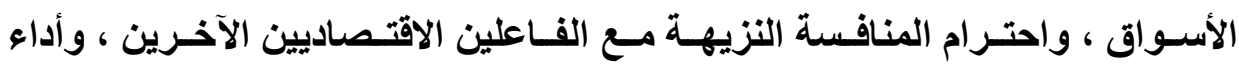
الالتزامات الضريبية بوجه خاص.

ومـع التسليم بتلك الحقيقة إلا أن الإقدام على تنظيم الاقتصاد التعـاوني عبر

المنصات الرقمية لا يبدو محاطاً بالنجاح؛ لأن هذا الاقتصاد يبدو كمـا أوضحنا متنوعـاً إلى حد كبير مـابين الاقتصاد الذي لا يهدف للربح والاقتصاد الذي يـهف إلى تحقيق

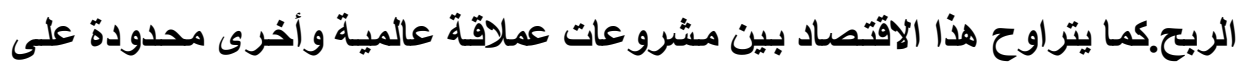
المستوى الوطني، ومن هنـا يكون التظظيم القانوني للاقتصاد التعاوني عبر المنصات الرقمية محاطاً بعقبات تحتاج روئية معمقة ، وهذا مـا يفسر لمـاذا لا يوجد حتى الآن لا يوجد تنظيم موحد لهذا النوع الجديد من الاقتصاد الذي فرضته تكنولوجيا المعلومات. إذ كان الاقتصاد التعاوني يستخدم المنصات الإليكترونيـة فِان تنظيمـه يتم من

خلال طريق شائك وطويل. 
عدد خاص بالمؤتمر الدولى السنوى العشرون أ.د / محمد محمد عبد اللطيف

\section{لالتمؤلف}

الأبحاث المتخصصة باللغة العربية:

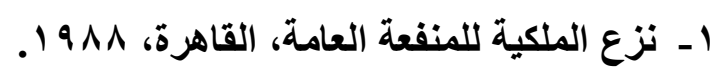

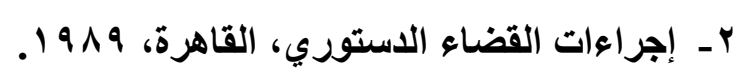

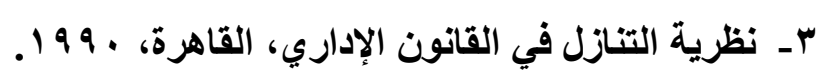

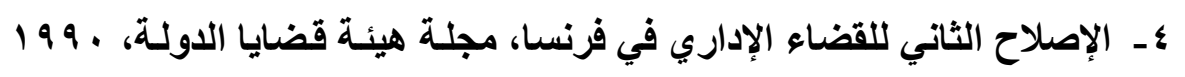

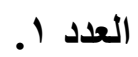

هـ التظظيم القـانوني لتمويـل الحيـاة السياسية فـى فرنسـا، دراسـة خاصـة عـن

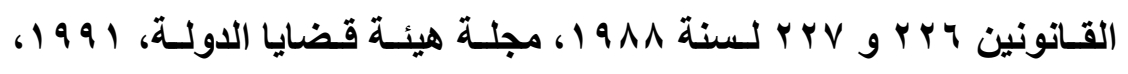

العدد با. الم.

7- دستورية حظر البــاء على الأراضـي الزراعيـة، تعليق على حكم المحكمـة

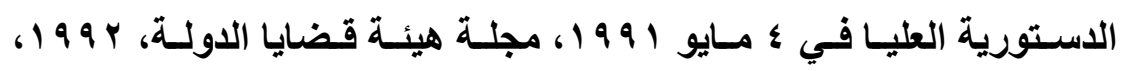

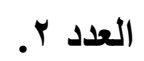

V- التصحيح التثريعي، القاهرة، اج9 9 ا ـ (الكتاب الحائز جائزة جامعة المنصورة

(التشجيعية).

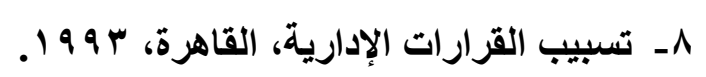

9- القيمة الاستورية لقرينة البراعة، تعليق على حكم المحكمة الدستورية العليا

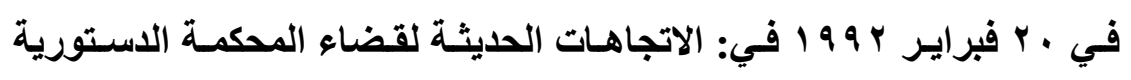

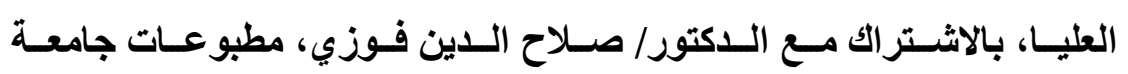

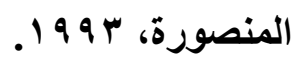


عدد خاص بالمؤتمر الدولى السنوى العشرون أ.د / محمد محمد عبد اللطيف

• ـ ـ قضية سوق روض الفرج، دراسة تحليلية نقدية لحكم المحكمة الإداريـة العليـا

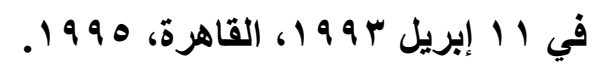
1 ا ـ حريـة الإذاعة المسموعة والمرئية، بحث مقدم إلى مؤتمر الإعلام والقـانون بكلية الحقوق جامعة حلوان، مجموعة أعمال المؤتمر، الجزء الأول، 99 9 19 ـ r ا ـ الـضمانات الدسـتورية في المجـال الـضريبي ،مطبوعـات جامعـة الكويــ، .1999

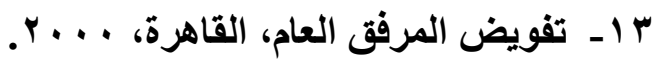

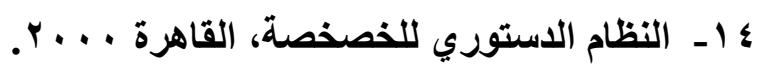

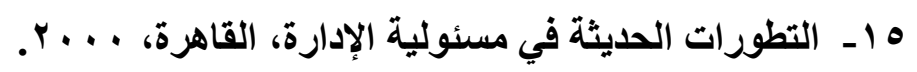

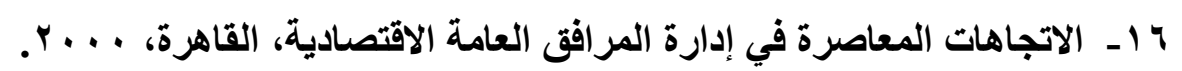

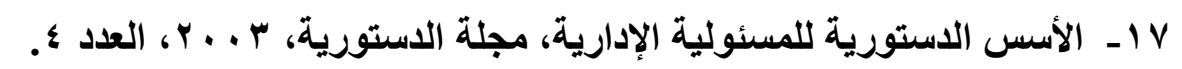

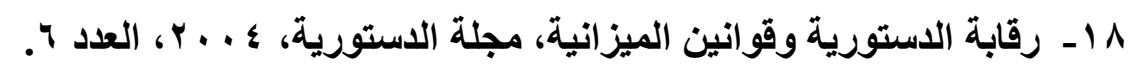

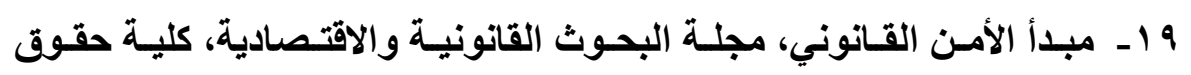

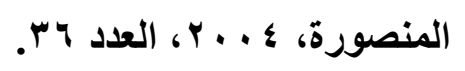

• † ـ أحكام تأمين الكوارث الطبيعية في القانون الإداري، مجلة الحقوق للبحوث

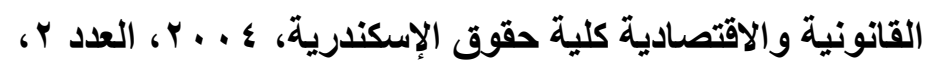

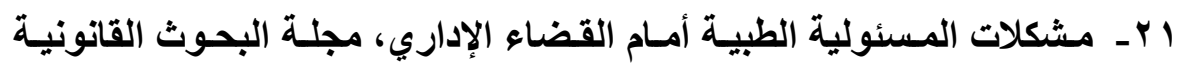

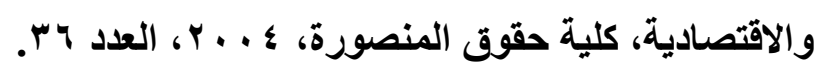

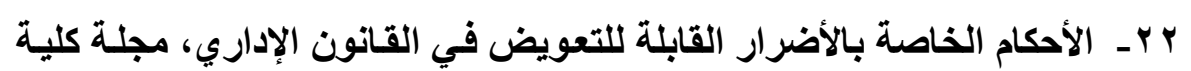

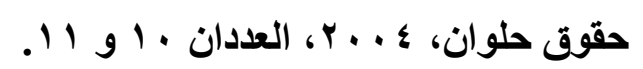

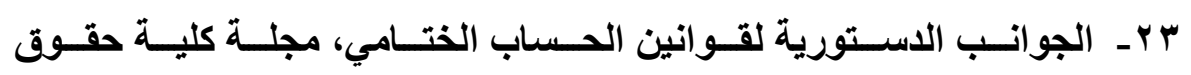

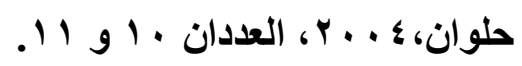


عدد خاص بالمؤتمر الدولى السنوى العشرون أ.د / محمد محمد عبد اللطيف

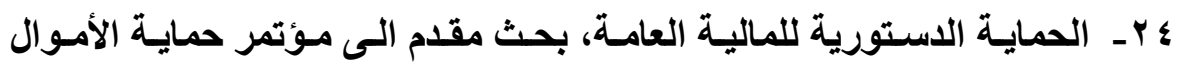
العامة، كلية حقوق بنها، مارس ؛ . . ب.

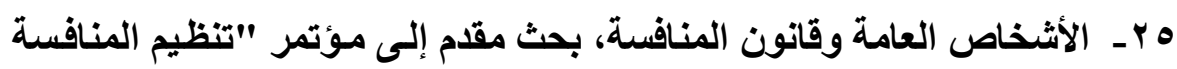

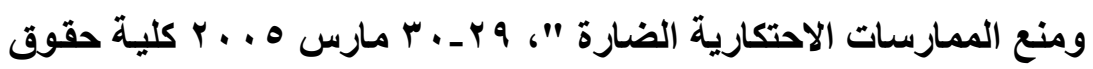

\section{المنصورة.}

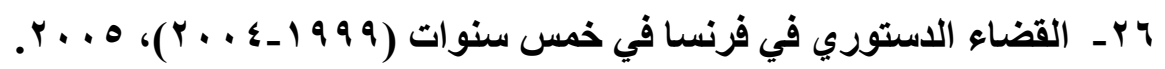

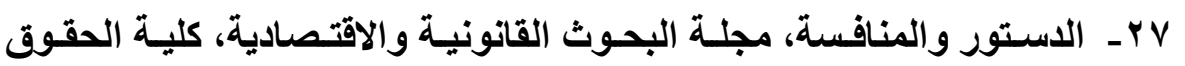

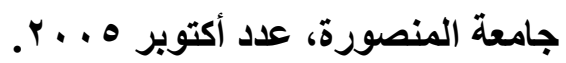

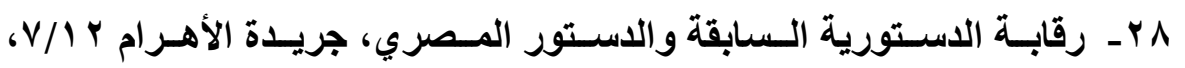

$$
. r .0 / v / 19
$$

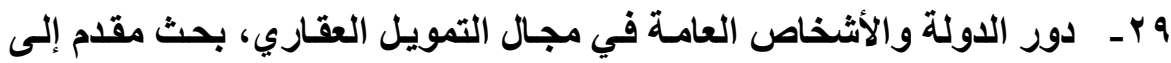

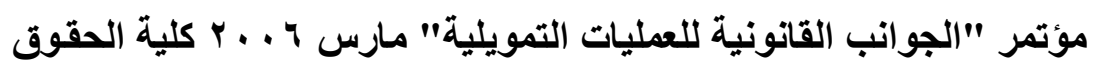
جامعة الكويت.

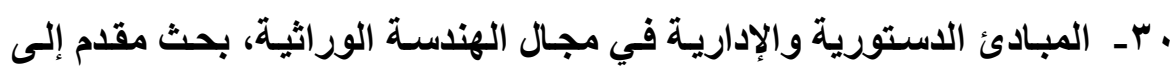
مـؤتمر "الجوانـب القانونيـة والاقتـصادية والشرعية لاسـتخدامات تقتيـات

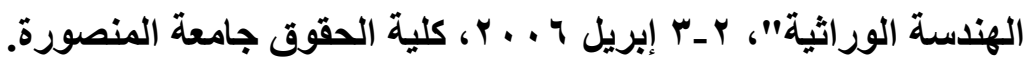
ابــ التعديلات الاستورية وقوانين الميزانية، بحث مقدم إلى مؤتمر " الإصلاح

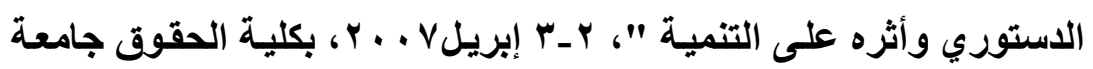
المنصورة.

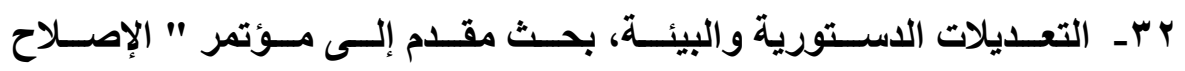

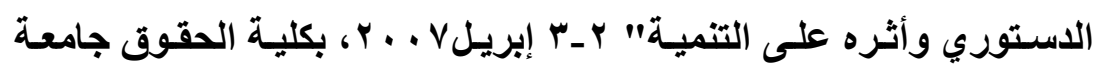
المنصورة. 
عدد خاص بالمؤتمر الدولى السنوى العشرون أ.د / محمد محمد عبد اللطيف

r r ـ الأسس الدستورية لقوانين الميزانية، مجلس النشر العلمي، جامعة الكويت

$$
r \cdot v
$$

ع r- الاستور الكويتي وخصخصة المرافق العامة وعقود المشاركة وعقود البنـاء

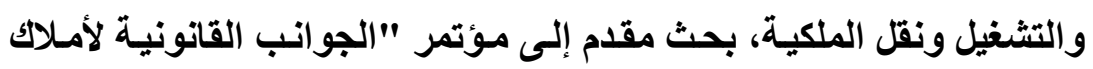

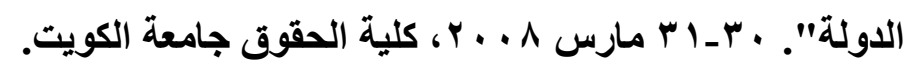

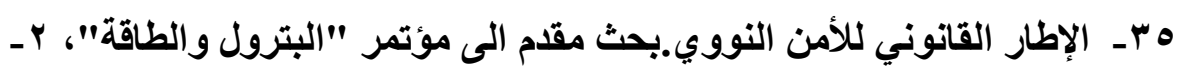
r ابريل ^ ^ . . r، كلية الحقوق جامعة المنصورة. وبـ سلطة تنظيم الأسواق المالية. الإطسار الاستوري والتنظيم التشريعي ،مجلة

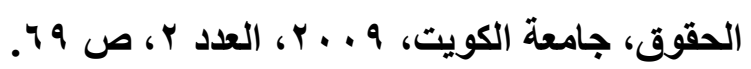

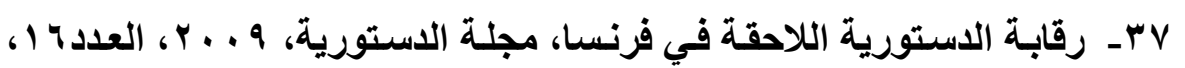
ص ص

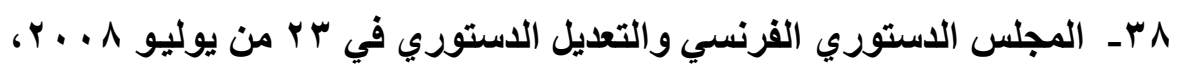

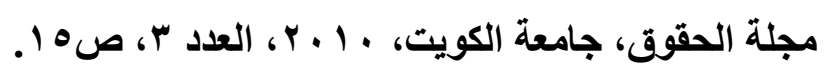

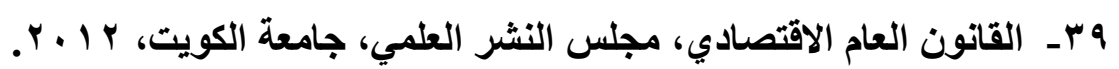

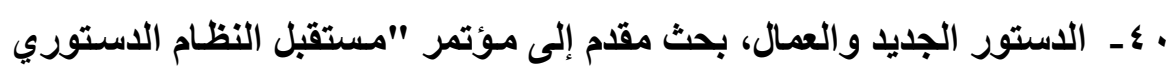

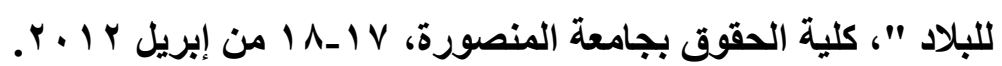

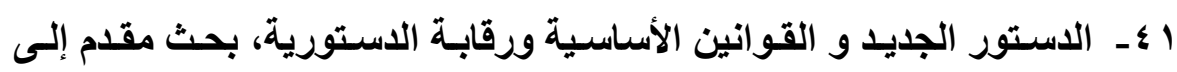

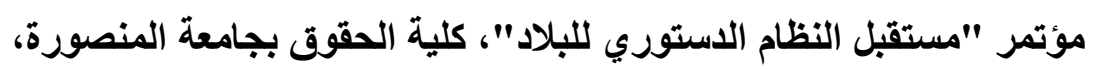

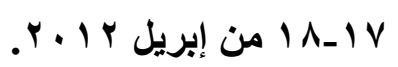

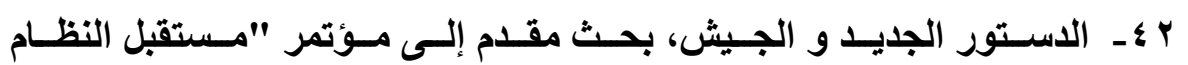

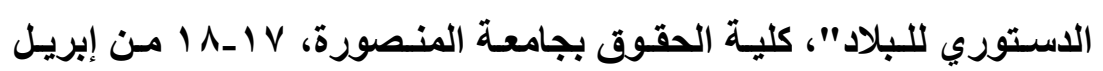


عدد خاص بالمؤتمر الدولى السنوى العشرون أ.د / محمد محمد عبد اللطيف

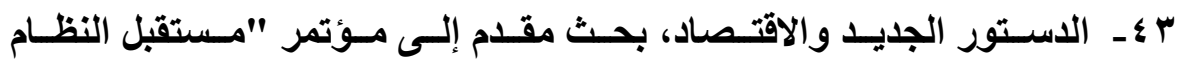

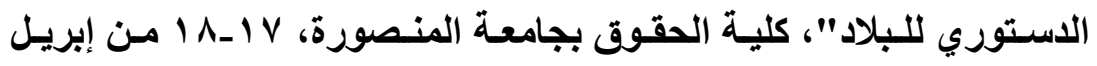

$$
\text { . } r \text {. Ir }
$$

ـ ـــ الطاقة النووية والقانون، مجلة عالم الفكر ،الكويت، المجلد إ؛، العدد الثالث

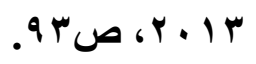

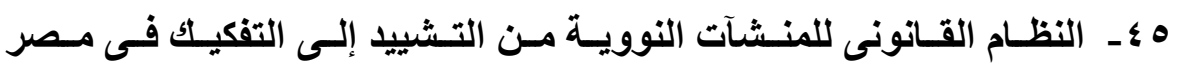
والإمارات، بحث مقدم إلى مؤتمر "الطاقة بين القـانون والاقتصاد"، كلية

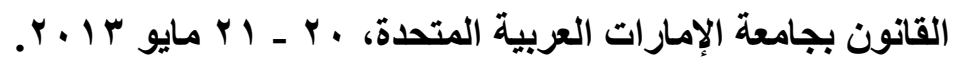

\ §ـ القانون الإداري للأموال، الكتاب الأول، الأملاك العامة ونزع الملكية للمنفعة

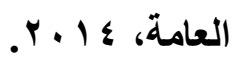

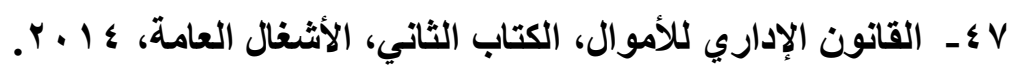
^ـ ـ الهيئة العربية للطاقة الذرية والإيراتوم، بحث مقدم إلى مؤتمر مصر والعالم

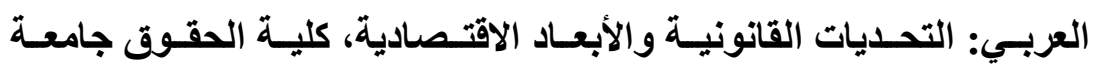

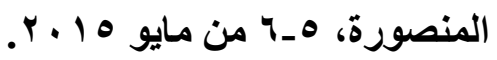

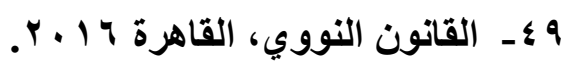

• •ـ المشروع النووي المصري ،الإطار القانوني والبنيان المؤسسي، بحث مقدم إلى مؤتمر الأبعاد القانونية والاقتصادية للمشروعات القومية، كلية الحقوق

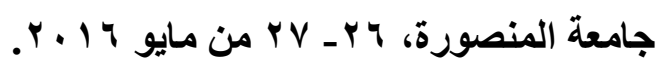

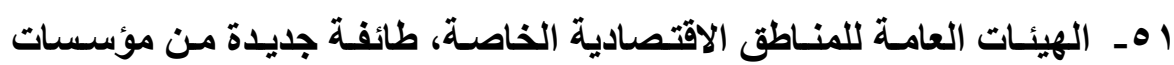

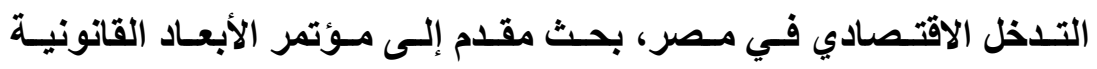

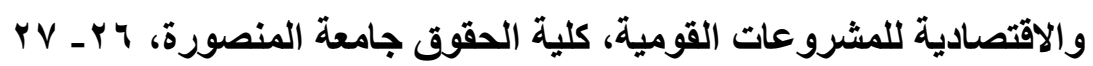

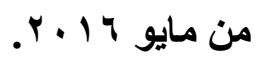


عدد خاص بالمؤتمر الدولى السنوى العشرون أ.د / محمد محمد عبد اللطيف

r ـ المرافق والمشروعات العامة الثقافية القومية، بحث مقدم إلى مؤتمر الأبعاد القانونية والاقتصادية للمشروعات القومية، كلية الحقوق جامعة المنصورة،

$$
\text { צr }
$$

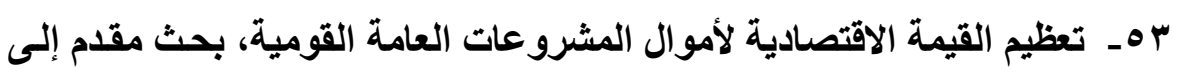

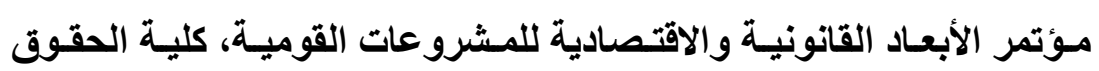

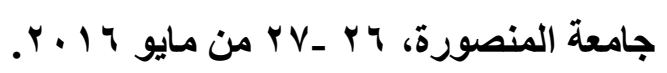

ـ ــ التظيم القانوني للهجرة الشرعية، بحث مقدم إلى مؤتثمر الأبعاد القانونية

للهجرة غير الثرعية وآثار ها على التنمية، كلية الحقوق بجامعة المنصورة،

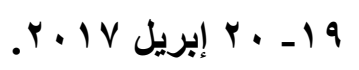

هـ ـ ضمانات المهاجرين غير الشرعيين في أوضاع الانتظار والاحتجـاز والإبعاد، بحث مقدم إلى مؤتمر الأبعاد القانونية للهجرة غير الشرعية وأثارهـا على الثى

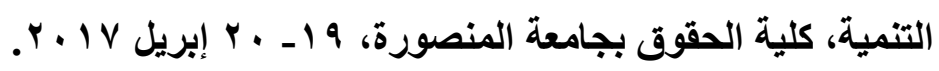

צهـ حقوق المهاجرين غير الشرعيين، بحث مقدم إلى مؤتمر الأبعاد القانونية

للهجرة غير الثرعية وآثارها على التنمية، كلية الحقوق بجامعة المنصورة،

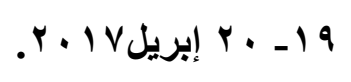

Vـ - جرائم الهجرة غير الثرعية بين الإطار الدستوري والتوجيه الأوروبي، بحث مقدم إلى مؤتمر الأبعاد القانونية للهجرة غير الثرعية، كلية الحقوق بجامعة الإطرة

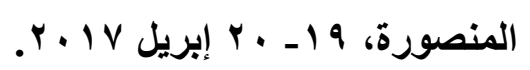

^هـ جزاعات سلطة تنظيم الأسواق المالية وضمانات المحاكمة المنصفة ، القاهرة

$$
r \cdot 1 \Lambda \text { ، }
$$

9هـ القانون الناعم قانون جديد للسلوك الاجتمـاعي ، مجلة عـالم الفكر،المجلس

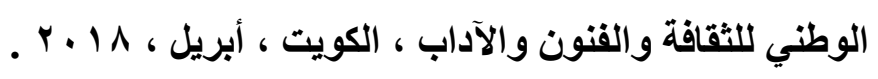

مجلتً البحوث القانونيت والإقتصاديت 
عدد خاص بالمؤتمر الدولى السنوى العشرون أ.د / محمد محمد عبد اللطيف

• צ- موسـوعة القـانون النـووي ، جـزعان ، دار الفــر والقـانون ؛ المنـصورة ،

$$
.19
$$

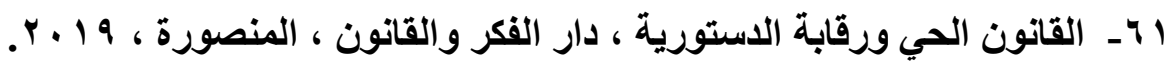
r r- الاستثمار والنظام العام الاقتصادي ، بحث مقدم إلمؤتمر العربي للاستثمار والتنميـة، نحـو بيــة تششريعية جاذبـة للاسـتثمار ، كليـة الحقـوق بجامعـة

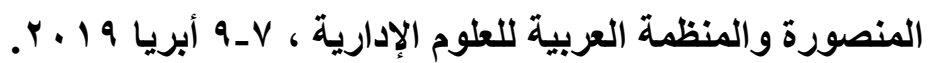

با7- الاستثمار والاقتصاد الدائري والتحول في الطاقة ، بحث مقدم إلى المؤتمر العربـي للاسـتثماروالتتمية ، نحـو بيئـة جاذبـة للاسـثثمار ، كليـة الحقـوق

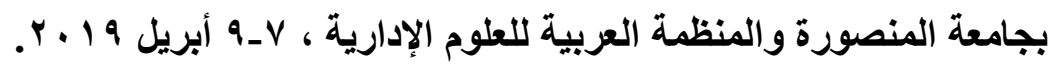
ع 7- الإجراءات الضريبية والتحول الرقمي، مصر وفرنسا نموذجًا، بحث مقدم إلى الى الندوة الدولية الإليكترونية بعنوان نظام الدفع والجباية المالية في ظل البيئة الإليكترونيـة التي نظمتها كليـة القـانون بجامعة القلوجـة بـالعراق، 10 مـن

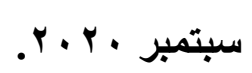

ه r- الوظيفـة الاجتماعيـة للشركات، المجلـة الدوليـة للفقهـه والقضاء والتشريع،

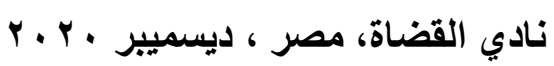

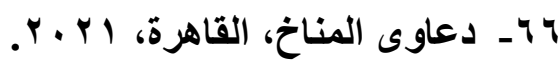

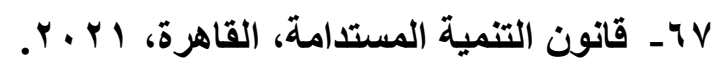

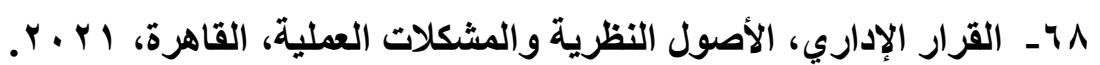

9 7ـ الإطــار القـانوني للاقتـصاد التعـاوني عبـر المنـصات الإليكترونيـة، بحـث

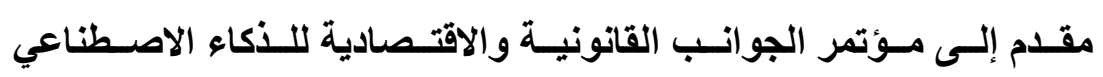

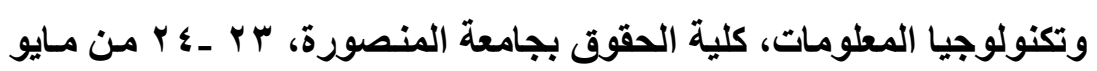




عد عد خاص بالمؤتمر الدولى السنوى العشرون أ.د / محمد محمد عبد اللطيف

• . - المسئولية عن الذكاء الاطناعي بين القانون الخـاص والقانون العام، بحث

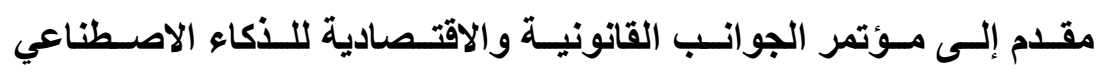

وتكنولوجيا المعلومات، كلية الحقوق بجامعة المنصورة، بr ـ ـ ـ من مـايو

.r. r

المراجع المتخصصة باللغة الفرنسية:

71- Le contentieux des élections parlementaires, thèse ، Université de Dijon, 1983 (Ouvrage récompensé par le Centre français de Droit comparé à Paris)

72- L'expropriation au pays des pyramides, Etudes foncières, Paris, décembre 1988

73- La protection constitutionnelle des droits économiques et sociaux en Egypte et en France, Arab Law quarterly, v. 19, 2004, P.225

74- La constitutionnalité de la législation sur la justice constitutionnelle au Koweït, Revue française de Droit constitutionnel, 2007, n. 69

75- La régulation du marché du crédit foncier en Egypte, Revue internationale de Droit comparé, 2008, n.1 
عدد خاص بالمؤتمر الدولى السنوى العشرون أ.د / محمد محمد عبد اللطيف

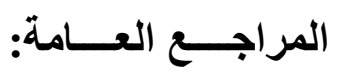

ل V - الحريـات العامـة، وحدة التـأليف والترجمـة والنشر بكليـة حقوق الكويـ، .1990

النظم السياسية، وحدة التـأليف والترجمة والنشر بكليـة حقوق الكويـ، -VV $199 V$

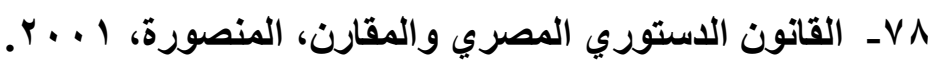

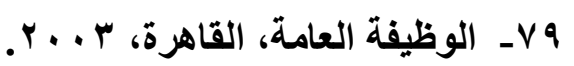

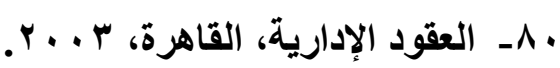

ایــ قـانون القـضاء الإداري، الكتــاب الأول، نظــام القـضـاء الإداري، القــاهرة، . $r .1$

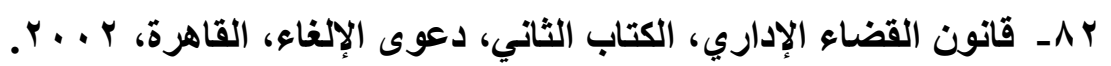

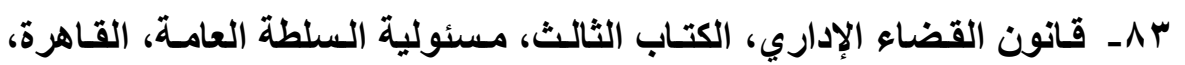
. . . \&

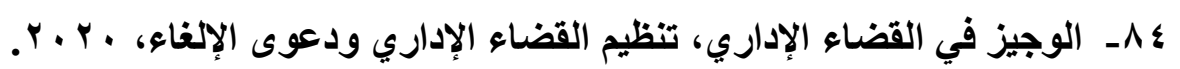

